\title{
Structural Transformation Options of the Saudi Economy Under Constraint of Depressed World Oil Prices
}

\author{
Salaheddine Soummane ${ }^{a}$, Frédéric Ghersi ${ }^{b}$, Franck Lecocq ${ }^{c}$ \\ a Corresponding author. CIRED, AgroParisTech, CIRAD, CNRS, EHESS, Ecole des Ponts ParisTech, Univ Paris-Saclay, UMR 8568. CIRED, 94736 \\ Nogent-sur-Marne, France. E-mail: salaheddine.soummane@kapsarc.org. \\ ${ }^{b}$ CIRED, AgroParisTech, CIRAD, CNRS, EHESS, Ecole des Ponts ParisTech, Univ Paris-Saclay, UMR 8568. CIRED, 94736 Nogent-sur-Marne, \\ France. E-mail: ghersi@centre-cired.fr. \\ ${ }^{c}$ CIRED, AgroParisTech, CIRAD, CNRS, EHESS, Ecole des Ponts ParisTech, Univ Paris-Saclay, UMR 8568. CIRED, 94736 Nogent-sur-Marne, \\ France. E-mail: lecocq@centre-cired.fr.
}

\begin{abstract}
We implement the hybrid (energy-economy) recursive-dynamic multisector IMACLIM model with important adaptations to Saudi macroeconomics. We design two scenarios reflecting both the Saudi Vision 2030 economic development program and Nationally Determined Contribution (NDC) to greenhouse gas mitigation: Continuity of previous plans to expand energy-intensive activities under maintained energy-pricing policies, versus Transformation by economic diversification away from hydrocarbon-related activities and fiscal and energypricing reforms. We show that, compared to Continuity, Transformation improves activity, employment and public budget outlooks, while considerably abating the energy intensity of GDP and total $\mathrm{CO}_{2}$ emissions. Our results thus point at the relevance of economic diversification as both a hedging strategy against international climate change mitigation depressing oil markets and a national climate mitigation strategy for Saudi Arabia. However, the successful advancement of the reforms necessary for diversification remains conditional to setting a suitable institutional framework for a competitive economy.
\end{abstract}

\section{KEYWORDS}

Economic diversification, General equilibrium, Oil-exporting country, Climate policy. 


\section{INTRODUCTION}

The implications of global mitigation policies for oil-exporting countries of the Middle East have generated considerable attention. There is a large consensus in the literature that a scenario of ambitious mitigation would depress oil prices. The drop is of $27 \%$ by 2030 in the Sustainable Development Scenario (SDS) of the International Energy Agency (IEA, 2017) compared to its less stringent New Policies Scenario (NPS). There is also widespread agreement that mitigation policies at global scale will reduce global oil demand. Comparatively, how demand for the conventional oil of the Middle East and thus how export revenues of Middle East producers may evolve, is less clear-cut. Johansson et al. (2009) and Persson et al. (2007) project gains as carbon pricing would drive unconventional resources out of the market under the condition of low oil-demand elasticity. Conversely, Bauer et al. (2016), Edenhofer et al. (2014), Waisman et al. (2013) estimate that oil-exporting countries in the Middle East will lose from the implementation of global mitigation policies, as will all oil-exporters.

The Kingdom of Saudi Arabia (KSA) is notoriously exposed to both volume and valuation risks, as oil revenues generated over $80 \%$ of both the country's exports and fiscal earnings between 2009 and 2018 (SAMA, 2018). Consequently, the KSA's communications to the United Nations Framework Convention on Climate Change (UNFCCC) have argued that global climate policies would deteriorate its economic outlook (Saudi Arabia, 2005; 2011; 2016a). Some strategies could mitigate adverse climate-policy effects on oil revenues (e.g., quota agreements to sustain prices, price cuts to increase market shares or monetary compensation under the climatenegotiation process) but may prove challenging to implement and transitory at best. Pershing (2000), Hvidt (2013) and Van de Graaf and Verbruggen (2015) affirm that economic diversification is the only viable development strategy for oil-exporting countries facing the structural decline of oil rent prompted by global lowcarbon transition.

Economic diversification away from oil extraction has been a constant objective of KSA policymakers since the 1970s (Saudi Arabia, 2016a). Most plans have focused on the development of energy-intensive industries to exploit the country's competitive advantage on energy costs. The latest plan-called Vision 2030-outlines a more comprehensive transformational strategy to drive the Saudi economy away from oil dependence (Saudi Arabia, 2016b). Although Vision 2030 expects oil and gas extraction to maintain an important role in the Saudi 
economy, the transformative aspect of the plan sets the relative weight of that activity to decrease as investment flows towards non-oil sectors. Besides, the plan orients diversification less towards energy-intensive industries and more towards services. Additionally, diversification beyond energy-intensive activities is the cornerstone of the KSA Nationally Determined Contribution (NDC) to the Paris Agreement (Saudi Arabia, 2015). However, Saudi NDC also considers an alternative scenario of limited diversification focused on energy-intensive industries.

The objective of the present paper is to assess the economic, fiscal, social and environmental implications of diversification of the Saudi economy under two scenarios reflecting those of the Saudi NDC. The test of two strategies is justified by the fact that successive development plans have so far failed to foster the emergence of a competitive non-oil private sector (Albassam, 2015), and that the latter objective continues facing considerable challenges, mostly regarding job creation (IMF, 2016a).

The methodological challenge of modeling the Saudi economy has been taken up in recent years. Al-Thumairi (2012), Al-Hawwas (2010) and De Santis (2003) assess static counterfactual scenarios, mostly of oil price shocks, with conventional computable general equilibrium (CGE) models. Blazquez et al. (2017) implement a stylized dynamic equilibrium model to estimate the long-run welfare impact of renewable energy penetration. Gonand et al. (2019) model overlapping generations in a similar dynamic framework to explore the long-run consequences of energy pricing reforms.

Compared to this corpus, our contribution is to implement a dynamic economy-wide model adapted to KSA macroeconomics, calibrated both statically and dynamically on hybrid economy/energy data and backed by bottom-up energy modeling (Ghersi, 2015; Hourcade et al. 2006). In this spirit, Soummane et al. (2019) developed the KLEM-KSA model to investigate the macroeconomics of reduced Saudi oil-export income at the 2030 horizon. They showed that structural weakening of the oil price would slow down Saudi growth and increase unemployment, while significantly cutting down trade-surplus accumulation and increasing the public debt. They then demonstrated how domestic energy-pricing reforms could mitigate some of these losses if they were partly recycled in higher investment, irrespective of their impact on energy intensity. The level of aggregation of their analysis only allowed for crude descriptions of both production activities (two aggregate sectors) and the secondary distribution of income (rough estimates of public budget balances, no assessment of debt accumulation). 
Comparingly, our modeling breaks down energy supply into four sectors and non-energy activity into nine sectors, thereby allowing exploration of diversification options. It also extends to the secondary distribution of income between households, firms, public administrations and the rest of the world, thus producing original outlooks on the Saudi national debt and its distribution across domestic agents. With this tool, we produce dynamic outlooks at medium-term horizons of yet unexplored macroeconomic scenarios combining sectoral diversification, energy-pricing and public budget reforms.

The rest of our paper is organized as follows. We present our modeling method in Section 2. In Section 3, we describe two mitigation scenarios inspired by the Saudi NDC, then comment on scenario results in Section 4. We conclude and highlight policy implications in Section 5.

\section{THE IMACLIM-SAU MODEL}

\subsection{Salient features}

IMACLIM is an economy-wide model representing the supply and demand of goods and services, with the specific purpose of articulating with engineering representations of the energy system to produce consistent energyeconomy outlooks (Ghersi, 2015; Hourcade et al., 2006, Ghersi and Hourcade, 2006). IMACLIM exists in a global multi-regional version (Crassous et al., 2006; Sassi et al., 2010) and in country-specific versions currently covering France (Hourcade et al., 2010; Le Treut, 2017; De Lauretis, 2017), South Africa (Schers et al., 2015), Brazil (Lefèvre et al., 2018) and India (Gupta et al., 2019, 2020).

The application of IMACLIM to Saudi Arabia, IMACLIM-SAU, is a dynamic simulation model picturing economic growth in yearly time steps as resulting from exogenous assumptions of labor endowment and productivity (the Harrod-neutral assumption on technical progress). The vector of domestic outputs at year $t, Y_{t}$, is a function of the stock of capital $K_{t}$, of the labor force $L_{t}$, and of the intermediate consumption of energy and non-energy resources. Capital stock dynamics follow the standard accumulation rule $K_{t+1}=(1-\delta) K_{t}+I_{t}$, with $\delta$ the depreciation rate, constant over the modeled horizon. Investment $I_{t}$ is the amount of non-energy output used 
to build up $K$ at period $t$. Beyond these core Solow-Swann specifications and similar to other country versions, IMACLIM-SAU deviates from the CGE standard by four salient features. ${ }^{1}$

Firstly, IMACLIM-SAU calibrates on original hybrid data reconciling national accounting statistics with energy flows and prices statistics. This allows maintaining dual accounting of energy flows in physical and monetary units backed by statistically relevant, agent-specific prices. Hybrid accounting has a significant bearing on benchmark ratios crucial to macroeconomic analysis: the cost shares of energy in productions, the budget share of energy for households and the breakdown of energy consumptions and $\mathrm{CO}_{2}$ emissions across sectors and agents (Combet et al., 2014; Le Treut, 2017).

Secondly, IMACLIM-SAU treats as exogenous all variables pertaining to the energy system. This feature stems from the model being designed to couple with bottom-up energy expertise (Ghersi, 2015). IMACLIM-SAU thus traces growth trajectories building around exogenous energy flows. The cost structure of energy supply beyond its own energy intensity, as well as the specific margins on all energy sales, are also exogenously adjusted to match assumptions on the dynamics of annualized investment, operational expenses, domestic consumer prices and trade prices. Such specifications allocate part of value-added to constrained energy expenses and part of primary factor endowments to constrained energy supply volumes. These constraints on volumes, costs, and prices weigh on economic growth.

Thirdly, IMACLIM-SAU simulates suboptimal growth pathways. One first deviation from optimal growth is that IMACLIM-SAU is a simulation model that builds on exogenous investment pathways not explicitly reflecting the intertemporal optimization of some welfare indicator. A second deviation is that the model, on top of exogenously constraining energy markets, considers imperfect non-energy markets in the form of both mark-up pricing and underutilization of labor. On the labor market, the inertia of real wages prevents full clearing i.e. induces equilibrium unemployment specified through a 'wage curve' correlating the unemployment rate and the

${ }^{1}$ Annex $A$ in the Online Appendix presents the formulary and reference tables of the model. Section 2, Annex A and Annex B in the Online Appendix draw from Soummane and Ghersi (2020), with a few corrections and modifications. 
real wage (Blanchflower and Oswald, 2005). The specification captures well the characteristic rigidity of Saudi wages (Devaux, 2013).

Lastly, IMACLIM-SAU is carefully adapted to Saudi macroeconomics. These are uncommonly specific regarding both investment and saving behavior, and the trade balance. On investment and savings, the use of the sovereign Saudi fund as a buffer against fluctuations of oil export revenues (AlKathiri et al., 2020) requires departing from the CGE standard of fixed savings driving investment. Variations of the sovereign fund amount to variations of national savings meant to smooth out the investment path of the Kingdom. IMACLIM-SAU reflects this macroeconomic policy by implementing the Johansen closure of national savings adjusting to some exogenous investment path, rather than the neoclassical closure of investment adjusting to national savings (Taylor and Lysy, 1979).

On the trade balance, both the currency peg that has been fixing the value of the Saudi Riyal (SAR) against that of the US dollar since 1986 and the sensitivity of Saudi exports to the global oil price forbid considering the neoclassical standard of an exogenous trade balance resulting from real effective exchange rate (REER) adjustments. One alternate specification is to consider a fixed ratio between Saudi and import prices as a proxy of the fixed exchange rate to the USD. However, statistics reveal that the REER of Saudi Arabia is not fixed, but correlated to the contribution of the trade balance to Saudi GDP. The reason for this correlation is the differentiated impacts of oil price fluctuations on Saudi versus foreign (especially the US) prices (Soummane et al., 2019). IMACLIM-SAU substitutes the correlation to the standard trade-balance constraint for those scenarios considering the maintained administration of domestic energy prices, i.e. our Continuity scenario (see Section 3 and Equation A-32a). Scenarios of energy-pricing reforms like our Transformation scenario, because they modify the Saudi REER through unilateral increases of production costs, require yet another trade specification. We follow the reasoning of Soummane et al. (2019)'s Annex B by dropping the correlation between the REER and the trade balance and forcing the ratio of the 'rental price' of domestic value-added to foreign prices of our Continuity scenario, in our Transformation scenario (Equation A-32b). 


\subsection{Model calibration}

We calibrate IMACLIM-SAU at its 2013 base year on the original 'hybrid' energy-economy dataset of Soummane and Ghersi (2019). Additionally, to improve the relevance of modeled trajectories, we perform dynamic calibration for the years 2014 to 2017 targeting GDP, unemployment, and trade balance statistics, under the constraint of observed investment efforts, energy flows, and prices.

The latter calibration targets macroeconomic variables common to IMACLIM-SAU and the compact KLEM-KSA model of Soummane et al. (2019). We therefore follow Soummane et al.'s (2019) procedure and refer to their Annex D.2 for its description. The static calibration is similar to that of KLEM-KSA but extends in two directions: the breakdown of activity in 13 sectors, four of which are energy sectors (Table 1), and the secondary distribution of income between households, firms, public administrations and the foreign 'rest-of-the-world' agent (see Annex B in the Online Appendix). 
Table 1: IMACLIM-SAU sectors

\begin{tabular}{|c|c|c|}
\hline Abbreviation & Goods and services & Specification \\
\hline OIL & Crude oil & Hybrid \\
\hline GAS & Natural gas & Hybrid \\
\hline REF & Refined petroleum products & Hybrid \\
\hline ELE & Electricity & Hybrid \\
\hline AGR & Agriculture, hunting, forestry, and fishing products & Non-hybrid \\
\hline MIN & Other mining products & Non-hybrid \\
\hline $\mathrm{CHM}$ & Chemicals and petrochemicals & Non-hybrid \\
\hline NMM & Non-metallic minerals (including cement) & Non-hybrid \\
\hline MAN & Manufactured products & Non-hybrid \\
\hline C\&S & Construction and services (commercial and public) & Non-hybrid \\
\hline WTP & Water transport services & Non-hybrid \\
\hline ATP & Air transport services & Non-hybrid \\
\hline OTP & Other transport services & Non-hybrid \\
\hline
\end{tabular}

'Hybrid' sectors rest on calibration data extending to satellite accounts of physical flows, which imply agent-specific prices (see Section 2.1 and Soummane et al., 2019).

\section{SCENARIO NARRATIVES AND PARAMETERIZATION}

Considering its level of sectoral and distributional detail, we limit our exploration to the 2030 horizon, where we can both sustain its parameterization with a mix of governmental and expert views, and assume prolongation of KSA macroeconomics, particularly the currency peg to the USD. At that horizon, we focus on two contrasted scenarios.

\subsection{Energy-intensive development with limited diversification: The Continuity scenario}

Since the establishment of the Royal Commission for Jubail and Yanbu (RCJY) in 1975, the KSA has invested heavily in energy-intensive industries. The expansion of such industries benefited from two comparative 
advantages, namely integration with oil and gas extraction and low regulated energy prices. ${ }^{2}$ In 2004,2009 and 2015, the RCJY successively grew with the Jubail II and Yanbu II projects, the Ras Al Khair city dedicated to mining activities and the Jazan city dedicated to downstream activities. The Vision 2030 program, although a strategic plan to reduce the Kingdom's reliance on oil, still identifies activities related to hydrocarbons as pillars of the economy producing revenue crucial to the plan's success.

Our Continuity scenario prolongs this trend of strong development of energy-intensive industries under national climate policy action of lesser ambition, corresponding to the alternative scenario ("scenario 2") of the Saudi NDC (Saudi Arabia, 2015). It assumes unchanged energy-price regulations resulting in weak energy-efficiency gains (see Annex $C$ in the Online Appendix) combined to export stimuli as main policy drivers of the further expansion of energy-intensive industries. We translate the latter assumption in IMACLIM-SAU by acting on exogenous export trends (see Equation A-30 of Annex A in the Online Appendix), which modify sectoral activity and consequently, investment flows. We focus export-trend boosts on three sectors explicitly mentioned in "scenario 2" of the Saudi NDC, namely petrochemicals (CHM), mining (MIN) and cement (NMM). ${ }^{3}$

Saudi petrochemical exports grew rapidly in recent years and currently account for around $60 \%$ of non-oil exports earnings (SAMA, 2018). Although their growth slowed down following the oil price slump of 2015 and 2016 , it recovered in 2017 , recording a rate of $+12.8 \%$. This rate is only slightly above its $+10.7 \%$ annual average since 2005. Our Continuity scenario assumes that the latter average prevails up to 2030 . The strong dynamics are expected to proceed from the combination of increased current productions and the development of new productions (Jadwa, 2017).

\footnotetext{
${ }^{2}$ For example, Moya and Boulamanti (2016) report that the price of natural gas for some industrial activities in Saudi Arabia is one tenth what it is in Europe.

${ }^{3}$ Due to lack of data, we drop metal production as a distinct sector although it is cited in the Kingdom's NDC.
} 
The MIN sector has significant untapped potential that the government is willing to mobilize (MGI, 2015). Recent figures show spectacular increases of minerals outputs and exports. ${ }^{4}$ Our Continuity scenario assumes that MIN exports grow at 7.1\% per year between 2013 and 2030, reflecting the upper bound of MGI (2015).

Finally, the cement sector (NMM) has long been subject to an export ban, but the recent ban lift and the dynamics of adjacent markets, especially those in current or foreseeable reconstruction phases (e.g., Iraq, Yemen, and Syria) could boost the sector's exports. Our Continuity scenario therefore assumes NMM exports increasing at the same $7.1 \%$ annual rate as mineral exports.

\subsection{Proactive economic diversification compatible with higher climate pledges: The Transformation scenario}

Our Transformation scenario builds on the success of horizontal diversification plans and their compatibility with stronger climate commitments, i.e., reflects the central scenario of the Saudi NDC (Saudi Arabia, 2015) and the Vision 2030 program (Saudi Arabia, 2016b). It relies on the reform of energy prices to reduce opportunity costs incurred from domestic rather than international energy sales and to stimulate energy-efficiency gains (see Annex C.1 in the Online Appendix), and on the promotion of manufacturing and service activities as main drivers of transformation of the Saudi economy.

For decades, Saudi manufacturing has been facing competitiveness hurdles like technology gaps, inadequate labor skills and the lack of dedicated infrastructures (El Mallakh, 2015). To overcome such barriers, the Saudi government founded the Industrial Clusters (IC) state agency, which means to identify, support, and activate industrial investment opportunities. National and regional contexts provide promising opportunities for the automotive industry, which would integrate with related upstream branches such as high-grade plastics. HSBC (2018) projects a dynamic annual increase for Saudi transport equipment, machinery and other manufactured exports at around $10 \%$ per year on average from 2017 to 2030 . We retain this accelerated trend for the exports of the MAN sector of our Transformation scenario.

\footnotetext{
${ }^{4}$ https://www.export.gov/apex/article2?id=Saudi-Arabia-Mining-and-Minerals.
} 
Turning to services, we consider tourism and finance given the Kingdom's background and regional experiences. Exports of touristic activities account for most of services exports and almost 6\% of total exports in 2013 (CDSI, 2014). In the next decade, tourism is expected to grow rapidly, increasing its contribution to GDP, employment, and trade (Al Yousif and Al Bakr, 2017). Indeed, the KSA plans to reach 30 million visitors for Umrah alone by 2030, up from the current eight million (Saudi Arabia, 2016b). Exports of insurance and financial services account for only $17 \%$ of total Saudi services exports, compared with almost $50 \%$ for Bahrain, ${ }^{5}$ where they contributed to the decreased dependence on hydrocarbon revenues (Callen et al., 2014). In our Transformation outlook, we consequently set Construction and Services (C\&S) exports to grow at an annual rate of $6.7 \%$. This figure is close to the average growth of religious tourism between 2005 and 2014 (MGI, 2015) and reflects its targeted increase up to 2030 (Saudi Arabia, 2016b).

One additional dimension of Transformation regards public finances. The Saudi government currently derives income mostly from companies of the energy and energy-intensive sectors (see Annex B.1 in the Online Appendix). The Transformation scenario offers the opportunity to gradually disengage the government from direct economic activity by empowering the private sector (Saudi Arabia, 2016a). Fiscal reforms must compensate for this shift, which is an important dimension of the Kingdom's economic modernization. ${ }^{6}$ Our Transformation outlook consequently considers the gradual increase of corporate taxes from the calibration rate of $2.5 \%$ (the Zakat) to the current world average of $23.0 \%$ (Tax Foundation, 2018) by 2030. Although the increase is substantial, the 2030 rate remains below the current $27.4 \%$ average across $\mathrm{G} 20$ countries.

\subsection{Scenario parameterization}

In IMACLIM-SAU, economic growth primarily proceeds from exogenous increases of labor endowment and productivity. For these two drivers, both our scenarios replicate the assumptions of Soummane et al. (2019) reflecting projections by the International Labor Organization and Oxford Economics. The resulting trend of

\footnotetext{
${ }^{5}$ Source: The World Bank statistics at https://data.worldbank.org/indicator/BX.GSR.INSF.ZS?view=chart.

${ }^{6} \mathrm{MGI}(2015, \mathrm{p} .112)$ argues that the KSA should consider the "introduction of a modern system of taxation, along the lines of fiscal systems common to all G20 emerging economies".
} 
efficient-labor growth is $+2.2 \%$ per year, compounding into a potential $45.7 \%$ increase of real GDP between 2013 and 2030 (Table 2).

We exposed in sections 3.1 and 3.2 how our scenarios rest on differentiated export trends. In each scenario, we apply to all not-singled-out non-energy sectors a default trend equal to the aggregate export-trend assumption of Soummane et al. (2019), which reflects growth projections for the main export markets of the Middle East and North Africa by the IMF (2016b). The favorable trade impulses of target sectors must not be considered incremental sources of growth. They are rather forced alternative allocations to activities of the country's primary factor endowments, while the main growth driver of efficient-labor increases is unaffected by scenarios. The compared merits of the two allocations hang on the compared input structures and ex-ante international competitiveness of targeted sectors, which determine their abilities to concretize the potential growth embedded in efficient-labor dynamics.

On energy, both scenarios share a common international oil-price trajectory consistent with ambitious global reductions of $\mathrm{CO}_{2}$ emissions highlighting the challenge facing oil-dependent economies. Beyond dynamic calibration years, i.e., from 2018 to 2030, we use the price trajectory of the Sustainable Development Scenario of the International Energy Agency (IEA, 2017). By contrast, as presented in sections 3.1 and 3.2 scenarios diverge on domestic energy prices. The Continuity scenario assumes maintained regulation at current real levels while the Transformation scenario considers ambitious reforms (see Annex C.1 in the Online Appendix). They consequently diverge on induced energy-efficiency gains (see Annex C.2 in the Online Appendix). Another distinction between scenarios is the Saudi strategy concerning crude oil production and exports. In the Continuity scenario, we assume that the KSA sticks to its projected output according to IEA (2017). Under this assumption, output reaches 12.7 million barrels per day by 2030 , which is close to the current production capacity of the Kingdom. Oil exports endogenously result from the difference between output and domestic consumption. In the Transformation scenario, we choose to maintain oil exports at their levels of the Continuity scenario by adjusting output, taking account of domestic demand. Thus, the KSA avoids any 'market-flooding' strategy (see Annex C.4 in the Online Appendix) that might have negative effects on oil prices (Blazquez et al., 2017).

Lastly, both scenarios reflect the introduction by the Kingdom of a value-added tax (VAT) at $5 \%$ in 2018 , which they maintain up to 2030. Transformation additionally increases the corporate tax rate exponentially from its 
$2.5 \%$ value of 2017 to $23 \%$ in 2030 (see Section 3.2). To account for potential feedbacks from contrasted publicbudget performances, we cap public surplus at 1\% of GDP and assume that extra net public income is redirected to supplemental investment.

Table 2: Main scenario parameters

\begin{tabular}{|c|c|c|c|c|c|}
\hline \multirow[b]{2}{*}{ Macroeconomic drivers } & \multirow{2}{*}{$\begin{array}{c}\text { Calibration } \\
2013\end{array}$} & \multicolumn{2}{|c|}{------Continuity------ } & \multicolumn{2}{|c|}{----Transformation---- } \\
\hline & & 2030 & AAGR $^{a}$ & 2030 & AAGR \\
\hline Labor endowment (index) ${ }^{\mathrm{b}}$ & 1.00 & 1.38 & $+1.9 \%$ & 1.38 & $+1.9 \%$ \\
\hline Labor productivity & 1.00 & 1.05 & $+0.3 \%$ & 1.05 & $+0.3 \%$ \\
\hline Efficient Labor (index) ${ }^{c}$ & 1.00 & 1.46 & $+2.2 \%$ & 1.46 & $+2.2 \%$ \\
\hline Structural change drivers & 2013 & 2030 & AAGR & 2030 & AAGR \\
\hline Default export trend ${ }^{d}$ & 1.00 & 1.76 & $+3.4 \%$ & 1.76 & $+3.4 \%$ \\
\hline MIN export trend & 1.00 & 3.20 & $+7.1 \%$ & 1.76 & $+3.4 \%$ \\
\hline $\mathrm{CHM}$ export trend & 1.00 & 4.19 & $+8.8 \%$ & 1.76 & $+3.4 \%$ \\
\hline NMM export trend & 1.00 & 3.20 & $+7.1 \%$ & 1.76 & $+3.4 \%$ \\
\hline MAN export trend & 1.00 & 1.76 & $+3.4 \%$ & 3.86 & $+8.3 \%$ \\
\hline C\&S export trend & 1.00 & 1.76 & $+3.4 \%$ & 3.00 & $+6.7 \%$ \\
\hline Energy system parameters & 2013 & 2030 & AAGR & 2030 & AAGR \\
\hline $\begin{array}{l}\text { World oil price } \\
\text { (2016 USD per barrel) }\end{array}$ & 108 & 69 & $-2.6 \%$ & 69 & $-2.6 \%$ \\
\hline Domestic energy prices & Regulated & \multicolumn{2}{|c|}{ Unreformed $^{\mathrm{e}}$} & \multicolumn{2}{|c|}{ Reformed $^{f}$} \\
\hline Crude oil output (Mtoe) & 454.4 & \multicolumn{2}{|c|}{625.6} & \multicolumn{2}{|c|}{ Endogenous } \\
\hline Crude oil exports (Mtoe) & 381.9 & \multicolumn{2}{|c|}{ Endogenous } & \multicolumn{2}{|c|}{ Equal to Continuity } \\
\hline Energy efficiency & - & \multicolumn{2}{|c|}{ Low gains ${ }^{\mathrm{e}}$} & \multicolumn{2}{|c|}{ High gains ${ }^{\mathrm{e}}$} \\
\hline Fiscal parameters & 2013 & 2030 & AAGR & 2030 & AAGR \\
\hline Corporate income tax rate & $2.5 \%$ & $2.5 \%$ & $0 \%$ & $23.0 \%$ & $12.3 \%$ \\
\hline Value-added tax rate & $0 \%$ & \multicolumn{2}{|c|}{ 5\% (from 2018 on) } & \multicolumn{2}{|c|}{ 5\% (from 2018 on) } \\
\hline
\end{tabular}

${ }^{a}$ AAGR is the average annual growth rate from 2013 to 2030. Drivers other than structural change drivers have non-constant annual growth rates available from the authors upon request.

${ }^{b}$ Labor endowment is reported as index following common CGE practice (see e.g., Rutherford, 1999) and to clarify the computation of the efficient labor index (see below). It figures in full-time equivalents in the model (see Table A1 of online appendix).

c Efficient labor gains are the product of labor endowment and labor productivity gains.

${ }^{\mathrm{d}}$ Default trend applies to non-energy sectors unless otherwise specified.

e See Annex C.1 in the Online Appendix.

${ }^{f}$ See Annex C.2 in the Online Appendix.

\section{SCENARIO RESULTS}

We implement the two scenarios of Section 3 in IMACLIM-SAU running in annual steps from 2013 to 2030 . In the following subsections, we report on macroeconomic indicators, public accounts dynamics, energy consumptions 
and carbon emissions. For reference purposes, we synthesize below the main simulation results at end-horizon

(Table 3). Annex D in the Online Appendix provides some sensitivity analysis of the Transformation scenario.

Table 3: Summary of modeling results at 2030 horizon

\begin{tabular}{|c|c|c|c|c|}
\hline Indicator & $\begin{array}{r}\text { Calibration } \\
2013\end{array}$ & $\begin{array}{r}\text { Continuity } \\
2030\end{array}$ & $\begin{array}{r}\text { Transformation } \\
2030\end{array}$ & $\begin{array}{r}2030 \text { variation } \\
\text { from Cont. to } \\
\text { Transf. }\end{array}$ \\
\hline Real GDP, Bn 2013 SAR & 2,773 & 3,973 & 4,025 & $+1.3 \%$ \\
\hline Trade balance, \% GDP & $+24.6 \%$ & $+9.8 \%$ & $+5.6 \%$ & -4.3 pts \\
\hline $\begin{array}{l}\text { Cumulated 2013-2030 trade } \\
\text { surplus, Bn } 2013 \text { USD }\end{array}$ & - & 1,183 & 994 & $-16.0 \%$ \\
\hline Unemployment rate & $5.6 \%$ & $8.6 \%$ & $6.9 \%$ & $-1.7 \mathrm{pts}$ \\
\hline $\begin{array}{l}\text { Public budget balance, } \\
\% \text { GDP }\end{array}$ & $+5.6 \%$ & $-5.2 \%$ & $+1.0 \%$ & $+6.2 \mathrm{pts}$ \\
\hline $\begin{array}{l}\text { Net public debt, } \\
\% \text { GDP }\end{array}$ & $-95.9 \%$ & $+14.9 \%$ & $-21.0 \%$ & -35.9 pts \\
\hline $\mathrm{CO}_{2}$ emissions, $\mathrm{Mt}$ & 502 & 913 & 405 & $-55.6 \%$ \\
\hline
\end{tabular}

Sources: Calibration data (see Section 2.2), IMACLIM-SAU simulations. "Pts" stands for percentage points.

\subsection{Macroeconomics}

The Continuity and Transformation scenarios project real GDP growth from 2013 to 2030 at $43.2 \%$ and $45.1 \%$ respectively, i.e. 2.5 points below potential (efficient-labor) growth for the former scenario versus 0.6 points below potential growth for the latter. The key to the performance of Transformation is in the changed sectoral allocation of primary factors of production via structural change, as well as in the additional investment effort that its public budget performance allows funding.

Transformation channels an increasing share of investment towards non-energy-intensive sectors. In 2030, capital stocks of the MAN and C\&S activities end up $12.6 \%$ and $6.2 \%$ above their levels under Continuity, respectively. At that year, MAN and C\&S mobilize $8.0 \%$ and $85.2 \%$ of the non-energy capital stock. ${ }^{7}$ The shares are respectively 0.7 percentage points (pts) and 3.5 pts lower under Continuity. Conversely, Continuity

\footnotetext{
${ }^{7}$ The share of the capital stock mobilized in energy sectors stems from the exogenous energy trajectories backing each scenario (see Annex $\mathrm{C}$ in the Online Appendix).
} 
concentrates a higher share of capital stock in $\mathrm{CHM}$, at 7.5\% of the capital of non-energy sectors in 2030 versus 3.4\% under Transformation. These investment dynamics reflect the forced evolution of aggregate demand via export boosts, which reorients activity towards target sectors. Continuity increases the activity shares of MIN, CHM and NMM to $5.8 \%$ of GDP in 2030 against 3.1\% under Transformation. By contrast, Transformation induces a higher contribution from MAN and C\&S, who increase the sum of their shares to $57.4 \%$ of Saudi GDP in 2030 versus $52.1 \%$ under Continuity.

Activity dynamics drive the scenarios' consequences on employment. The MAN and C\&S sectors targeted by Transformation are labor-intensive compared to the CHM, NMM and MIN sectors targeted by Continuity. Compared to Continuity, the surges of activity in the C\&S and MAN sectors of the Transformation scenario therefore create significantly more employment (+424.3 thousand jobs) than the decreases of CHM, NMM and MIN activities destroy (-142.1 thousand jobs, see Table 4). The net difference totals 269.6 thousand jobs in 2030 , which translates into a 1.7-point gap between the unemployment rates of Transformation, at $6.9 \%$, and Continuity, at $8.6 \%$. 
Table 4: Net employment creation by sector, thousand full-time equivalents

\begin{tabular}{lrrr}
\hline Sector & $\begin{array}{r}\text { Continuity } \\
\text { 2030 versus 2013 }\end{array}$ & $\begin{array}{r}\text { Transformation } \\
\text { 2030 versus 2013 }\end{array}$ & $\begin{array}{r}\text { 2030 variation from } \\
\text { Cont. to Transf. }\end{array}$ \\
\hline OIL & 28.6 & 16.3 & -12.2 \\
GAS & 17.4 & -0.5 & -17.9 \\
REF & 11.2 & 10.4 & -0.8 \\
ELE & 31.8 & 12.1 & -19.7 \\
AGR & 101.1 & 142.3 & 41.3 \\
MIN & 2.8 & 0.8 & -2.0 \\
CHM & 145.6 & 20.7 & -124.9 \\
NMM & 77.6 & 62.3 & -15.2 \\
MAN & 121.8 & 216.9 & 95.1 \\
C\&S & 3107.7 & 3436.8 & 329.2 \\
WTP & 8.6 & 9.1 & 0.5 \\
ATP & 16.0 & 20.0 & 4.0 \\
OTP & 61.0 & 53.3 & -7.7 \\
Total & $3,731.1$ & $4,000.6$ & 269.6 \\
\hline SOUT
\end{tabular}

Source: IMACLIM-SAU simulations. Sector codes are those of Table 1. Numbers may not add up due to rounding.

General equilibrium effects must not be overlooked when interpreting such results. The higher labor intensities of MAN and C\&S imply lower average labor productivity under Transformation than under Continuity. Higher employment cannot therefore be the cause, but can only be the consequence of higher activity. The cause lies in the other primary-factor market, that of capital. Under Continuity, the high capital intensities of target sectors put strong pressure on capital demand, which induces sharp increases of capital costs. Transformation orients growth towards less capital-intensive sectors and secures enough public resources to allow increasing the investment effort in later projection years (see Section 4.2 below). At end-horizon, the ratio of capital to labor costs is thus $11.5 \%$ higher under Continuity than under Transformation, in part given higher real wages under Transformation. The increase of capital costs hampers both the purchasing power of households and the competitiveness of Saudi exports on international markets via producer prices. The adverse impact on activity is reinforced by the possibility of equilibrium unemployment. 


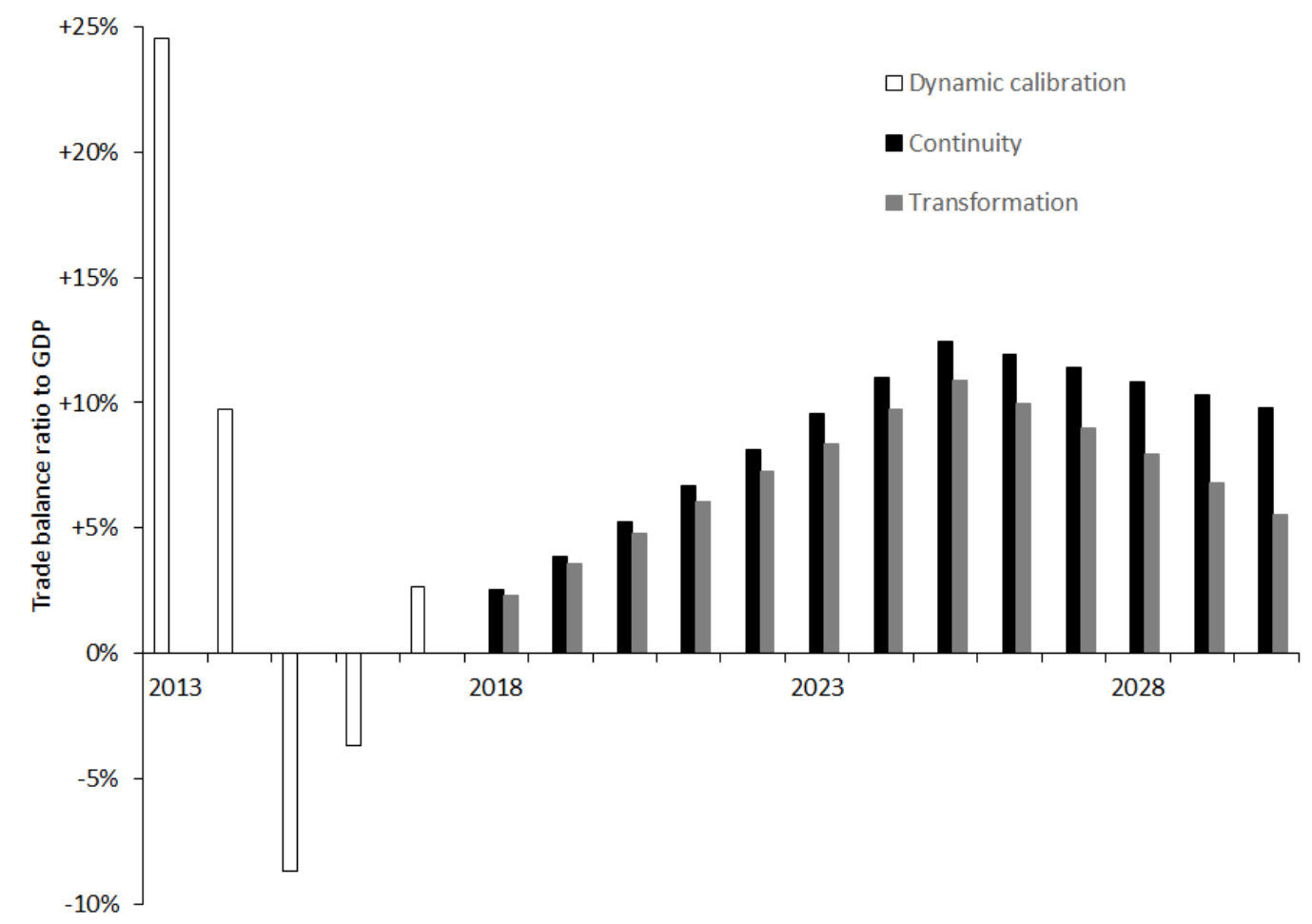

Sources: 2013 calibration value from SAMA (2018), 2013 to 2017 dynamics from authors' computations on International Monetary Fund and The World Bank data. IMACLIM-SAU simulations from 2018 to 2030.

Concerning international trade, both scenarios gradually improve the trade balance (Figure 1) from its 2015 lowest of $-8.7 \%$ of GDP up to 2025 thanks to the oil-price recovery projected by the SDS scenario of the IEA, then degrade it up to 2030 following the oil price decline (see Annex C.3 in the Online Appendix). The trade surplus ends up at $9.8 \%$ of Continuity GDP thanks to that scenario's impulse on energy-intensive exports. Exports of CHM increase by $275.7 \%$ in real terms from 2013 to 2030 and more than triple their contribution to total exports at current prices (28.8\% in 2030 versus $8.9 \%$ in 2013). MIN and NMM exports increase by $193.6 \%$ and $192.6 \%$. The gap to the forced trends of $+318.7 \%$ for $\mathrm{CHM}$ and $+220.0 \%$ for MIN and NMM (see Table 2 ) betrays the negative impact of the oil-price contraction below 2013 levels from 2015 on, on the competitiveness of Saudi products, which our original trade specification duly captures (see Section 2.1).

Under Transformation, the trade surplus contribution to GDP is lower in later years and ends at $5.6 \%$ in 2030 . The gradually weakening dynamics reflect exports of energy-intensive sectors suffering from energy-pricing reforms (see Annex C.1 in the Online Appendix). In 2030, the ratios of domestic to foreign prices of CHM and NMM under Transformation are thus $10.8 \%$ and $17.7 \%$ above their levels under Continuity. Consequently, real exports of MIN, CHM, and NMM grow by 54.1\%, 44.5\% and 39.7\% from 2013 to 2030, respectively, i.e. 
significantly less than their assumed trends of $76.6 \%$ outside relative-price shifts (see Table 2 ). Yet, the trade balance of the Transformation scenario benefits from a higher contribution of refined products, resulting from domestic energy savings redirected to exports (see Section 4.3). A recent application on Kuwait using a CGE model capturing its oil-dependent features matches some of our findings on how energy price reforms counter negative oil price shocks and foster economic diversification, thus boosting economic growth (Shehabi, 2020).

\subsection{Public accounts dynamics}

After running large surpluses during the high-oil-prices decade of 2004 to 2013, at almost 12\% of GDP on average, the Saudi public budget deteriorated from 2014 on and recorded a 15.8\% deficit in 2015 (SAMA, 2018). This makes the estimation of budget-related variables a crucial scenario result. The level of sectoral and distributional detail of IMACLIM-SAU offers significantly finer computations of the distributive effects of diversification policies, including on public accounts, than the rough estimates of Soummane et al. (2019).

Under our set of assumptions regarding public expenditures and income (see Equations A-19 to A-26), 2014 to 2017 budget balance estimates, although uncontrolled by dynamic calibration, are reasonably close to observed statistics (Figure 2). 


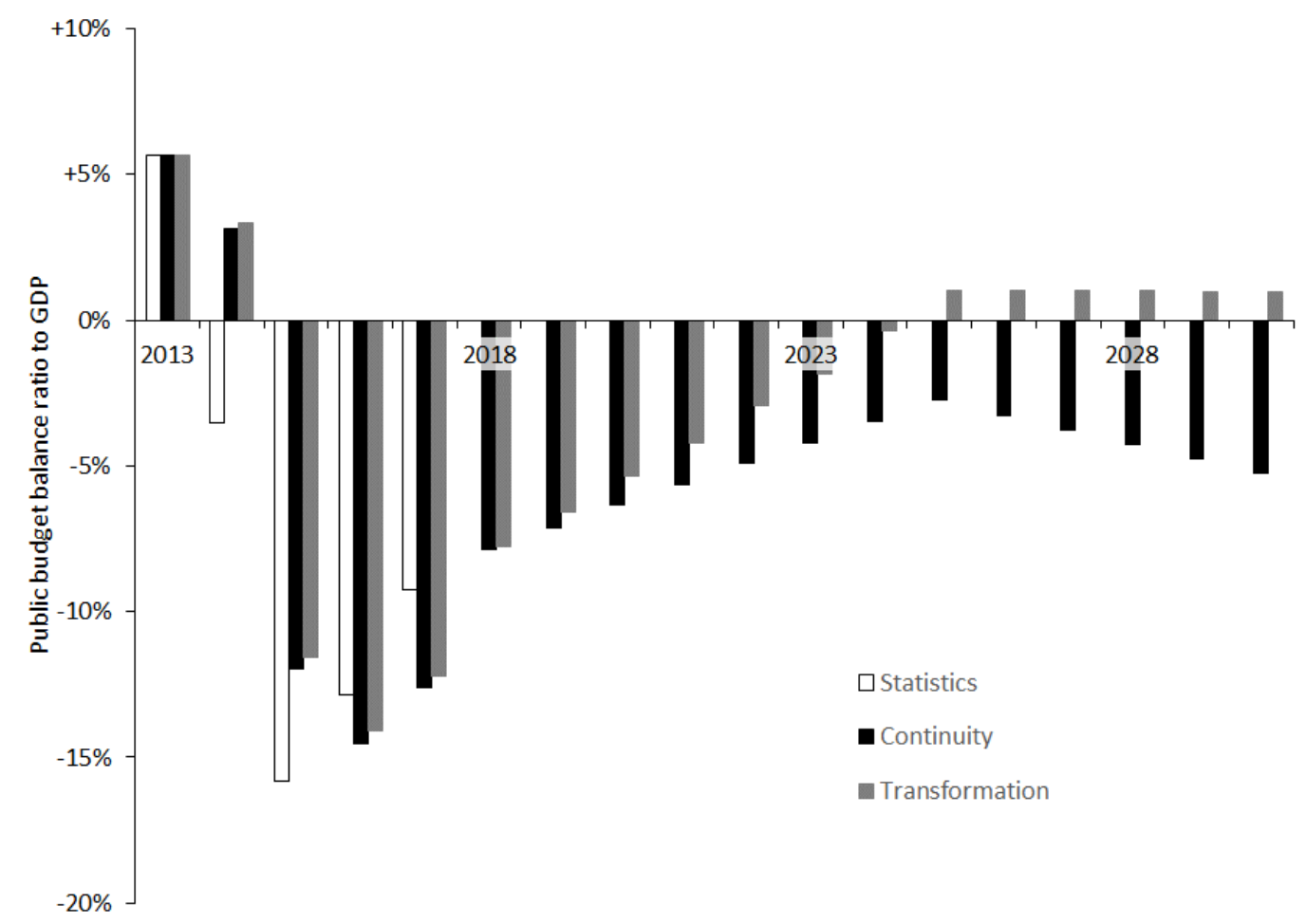

Sources: SAMA (2018) for 2013-2017 statistics and IMACLIM-SAU simulations. The 2014 public deficit that escapes IMACLIM-SAU reflects expenditures growing 15\% compared to 2013 mainly because of exceptional military expenditures (+21\%) and public investment (+22\%) (SAMA, 2018).

After 2017, the balances of both scenarios improve up to 2025, but following contrasted pathways. Under Transformation, the balance is close to equilibrium in 2024 and reaches its assumed $+1 \%$ surplus cap in 2025 (Figure 2). Under Continuity, the balance improves at a slower rate to reach its maximum of $-2.8 \%$ in 2025 , i.e. remains in deficit. It then marks the downturn of the price of oil projected by the IEA (see Section 3.3), which forbids public income to increase as fast as public expenditures broadly following general activity, to end on a 5.2\% deficit in 2030. Conversely, the steep increases of corporate taxes and energy prices allow the Transformation budget balance to stabilize at its $+1 \%$ cap up to 2030 . The excess surplus keeps in fact increasing and fuels additional investment reaching 2.9 GDP points in 2030, bringing investment expenses at 29.0\% of GDP compared to $26.1 \%$ under Continuity. By 2030, collected taxes amount to $15.3 \%$ of Transformation GDP versus $0.4 \%$ of Continuity GDP. The negative tax collection of Continuity points at the cost of maintaining energy subsidies, which outweigh total tax proceeds.

IMACLIM-SAU records the accumulation of public balances into public debt taking account of the initial net public credit and of the net interests that it raises. This allows estimating that, under Transformation, the KSA 
government will continue holding a consolidated creditor position up to 2030 , stabilized at around $21 \%$ of GDP from 2025 on when the budget surplus keeps at its $+1 \%$ cap. At that later period, our assumption of excess fiscal surplus acting as a growth catalyzer via extra investment opposes further improvement of the net public credit position. Notwithstanding, the contrast is strong with the Continuity scenario, whose systematic public deficits erode the net position. Erosion accelerates after 2025, when public deficits start aggravating. Net financial reserves are consumed by 2027 and the total net debt reaches 14.9\% of GDP in 2030 (Figure 3).

Figure 3: Net public debt under Continuity versus Transformation

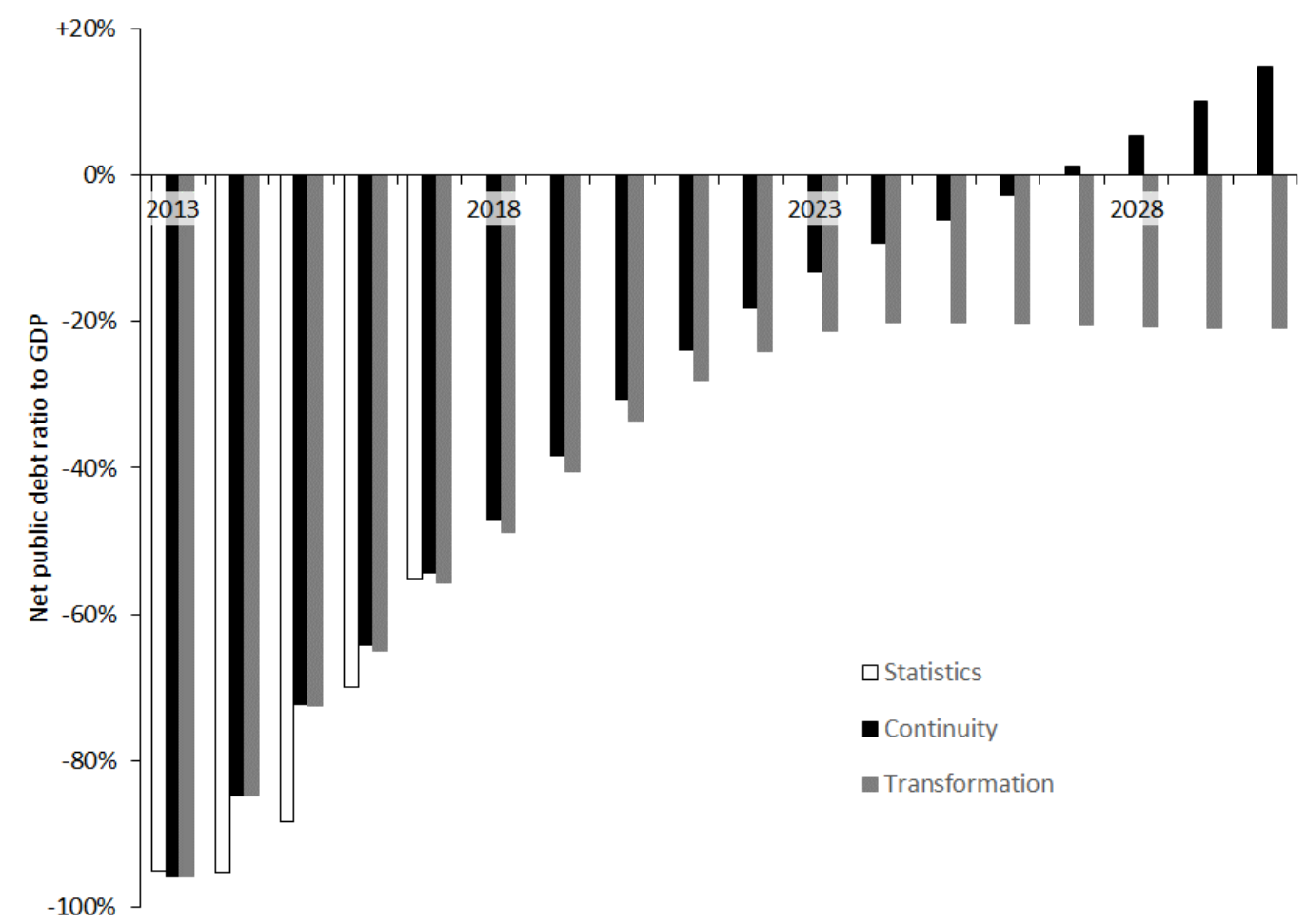

Sources: SAMA (2018) for 2013-2017 statistics and IMACLIM-SAU simulations.

The poor public-accounts performance of Continuity is all the more striking as Continuity favors energy-intensive activities, a major source of public income (see Annex B.1 in the Online Appendix). This is an important drawback of Continuity because the current large public savings serve as a buffer against oil price volatility. The KSA held 725.5 billion USD reserve assets in 2013, almost equivalent to that year's GDP. By the end of 2017, the sharp decline of the oil price from 2015 on had prompted public intervention that had reduced reserve assets by $31.6 \%$, to under USD 500 billion, and the gross public debt had climbed to $17.2 \%$ of GDP after the Kingdom's first issuance of international bonds in decades. Reliance on energy-intensive activities without any broad fiscal reform to expand the tax base turns out to jeopardize the capacity of the Kingdom to maintain such macroeconomic policy. 


\subsection{Energy consumption and $\mathrm{CO}_{2}$ emissions}

IMACLIM-SAU projections of the energy consumptions of productive activities reflect exogenous assumptions on sectoral energy intensities, which we extract from dedicated runs of the KAPSARC Energy Model (KEM) for the most important of them (see Annex C.2 in the Online Appendix).

Under Continuity, total Saudi energy consumptions rise 90.3\% above 2013 level by 2030 (Table 5). The increase partly results from our assumption that the maintained regulation of energy prices at low levels does not foster any energy-efficiency gains in non-energy activities. However, it is more than twice that of real GDP (see Section 4.1) and also reflects structural change as well as the rapid growth of households' consumptions (see Annex C.2 in the Online Appendix). Its bulk thus comes from energy-intensive industries and the power sector (Table 5).

By contrast, Transformation brings total Saudi consumption 1.9\% below 2013 level in 2030, or 243.1 million tons of oil-equivalent (Mtoe) below Continuity level. Around half the scenario gap comes from curtailed energy consumptions of CHM (-117.5 Mtoe) and an additional 40\% from ELE sector (-89.6 Mtoe). In CHM, abatement follows on significant output reductions in favor of MAN and C\&S. In ELE, the bulk of energy savings stems from the phase-out of crude oil as primary energy and its replacement by renewables - mainly solar PV, notably from 2023 on-and nuclear projected by KEM. Low-carbon options are not explicitly represented in IMACLIM-SAU but are captured by higher capital intensity and lower fossil intensity of the ELE sector. ${ }^{8}$ Under our assumption common to both scenarios of a moderate increase of refining capacities (see Annex C.4 in the Online Appendix), the combined sectoral energy savings of Transformation result in an additional 25.9 Mtoe or $29.3 \%$ exports of refined products (+4.6\% total energy exports) compared to Continuity in 2030.

\footnotetext{
${ }^{8}$ We use reference technology costs of IEA (2016) to compute the capital costs incurred by the investment chronogram projected by KEM.
} 
Table 5: Variations of domestic energy consumptions

\begin{tabular}{lrrr}
\hline \hline Sector & $\begin{array}{r}\text { Continuity } \\
\text { 2030 versus 2013 }\end{array}$ & $\begin{array}{r}\text { Transformation } \\
\text { 2030 versus 2013 }\end{array}$ & $\begin{array}{r}\text { 2030 variation } \\
\text { from Cont. to Transf. }\end{array}$ \\
\hline OIL & $\mathrm{n} / \mathrm{a}$ & $\mathrm{n} / \mathrm{a}$ & $\mathrm{n} / \mathrm{a}$ \\
$\mathrm{GAS}$ & $\mathrm{n} / \mathrm{a}$ & $\mathrm{n} / \mathrm{a}$ & $\mathrm{n} / \mathrm{a}$ \\
REF & $+58.5 \%$ & $+54.2 \%$ & $-2.7 \%$ \\
ELE & $+74.6 \%$ & $-41.8 \%$ & $-66.7 \%$ \\
AGR & $+25.7 \%$ & $+3.9 \%$ & $-17.4 \%$ \\
MIN & $+108.6 \%$ & $-15.7 \%$ & $-59.6 \%$ \\
CHM & $+246.1 \%$ & $-16.4 \%$ & $-75.9 \%$ \\
NMM & $+43.2 \%$ & $-9.2 \%$ & $-36.6 \%$ \\
MAN & $+28.7 \%$ & $-12.2 \%$ & $-31.8 \%$ \\
C\&S & $+46.3 \%$ & $+38.6 \%$ & $-5.3 \%$ \\
WTP & $+40.2 \%$ & $+20.0 \%$ & $-14.4 \%$ \\
ATP & $+57.3 \%$ & $+22.4 \%$ & $-22.2 \%$ \\
OTP & $+52.0 \%$ & $+18.3 \%$ & $-22.2 \%$ \\
Households & $+64.6 \%$ & $+28.2 \%$ & $-22.2 \%$ \\
Total & $+90.3 \%$ & $-1.9 \%$ & $-48.5 \%$ \\
\hline Soú & & &
\end{tabular}

Source: IMACLIM-SAU simulations. Sectoral non-commercial auto-consumptions are not recorded in the input-output framework of the model (i.e., oil and gas consumption within the oil and gas industry). From an energy balance perspective, the consumptions of the REF and ELE sectors are primary consumptions for transformation purposes, while other consumptions are final consumptions.

The energy mix of projected consumptions of the Continuity scenario is almost as carbon-intensive as that of 2013. Consequently, the $90.3 \%$ increase of consumptions over our projection period results in an $82.0 \%$ increase in $\mathrm{CO}_{2}$ emissions, which reach 912.8 million tons (Mt) in $2030 .{ }^{9}$ Comparatively, Transformation significantly abates $\mathrm{CO}_{2}$ emissions, which end 19.3\% below 2013 level in 2030 (Figure 4). In line with energy consumptions, the large increase in Continuity is mainly attributable to ELE and CHM, which account for $40.9 \%$ and $23.8 \%$, respectively (at 373.3 $\mathrm{Mt}$ and 217.3 Mt) of total Saudi $\mathrm{CO}_{2}$ emissions in 2030. At that horizon, emissions of these sectors are $76.3 \%$ and $234.3 \%$ higher than their respective 2013 levels. Conversely, the reduced $\mathrm{CO}_{2}$ emissions of Transformation largely reflect lower CHM activity and changes of the energy mix of power supply, which cut

\footnotetext{
${ }^{9}$ We track $\mathrm{CO}_{2}$ emissions as products of energy inflows and IPCC (2006) coefficients of $\mathrm{kg} \mathrm{CO}_{2}$ per TJ of consumption: 73,300 for crude oil; 56,100 for natural gas and for refined products; 77,400 in NMM and WTP (mainly fuel oil consumptions); 69,300 in CPS and OTP (mainly gasoline consumptions); 71,500 in ATP (mainly kerosene consumptions) and 73,300 in other sectors. Exceptions are the crude oil inflows into refineries (no emissions, computed for final uses of refined products) and the petrochemical sector, for which we consider IEA (2019) estimates of shares of stored carbon: $80 \%$ for refined products and $33 \%$ for natural gas. With this method, we estimate $2013 \mathrm{Saudi} \mathrm{CO}_{2}$ emissions at $501.6 \mathrm{Mt}$ i.e. $4.8 \%$ above the $478.6 \mathrm{Mt}$ reported in the EDGAR database (https://edgar.jrc.ec.europa.eu/overview.php?v=CO2ts1990-2013).
} 
down CHM and ELE emissions by $75.2 \%$ and $70.9 \%$ in 2030 compared with Continuity. In total, Transformation emissions end at $404.9 \mathrm{Mt}, 507.9 \mathrm{Mt}(-55.6 \%)$ below Continuity levels. The gap between the two scenarios is almost four times the Saudi NDC target of curbing down $\mathrm{CO}_{2}$ emissions by $130 \mathrm{Mt}$ in 2030 (Saudi Arabia, 2015). Thus, Saudi Arabia could largely increase its international commitments if it implemented the Transformation scenario while treating Continuity as the baseline from which reductions are assessed. Such a move would send a strong positive signal to the global community considering the importance of Saudi positions in international climate negotiations.

Figure 4: Total $\mathrm{CO}_{2}$ emissions under Continuity versus Transformation

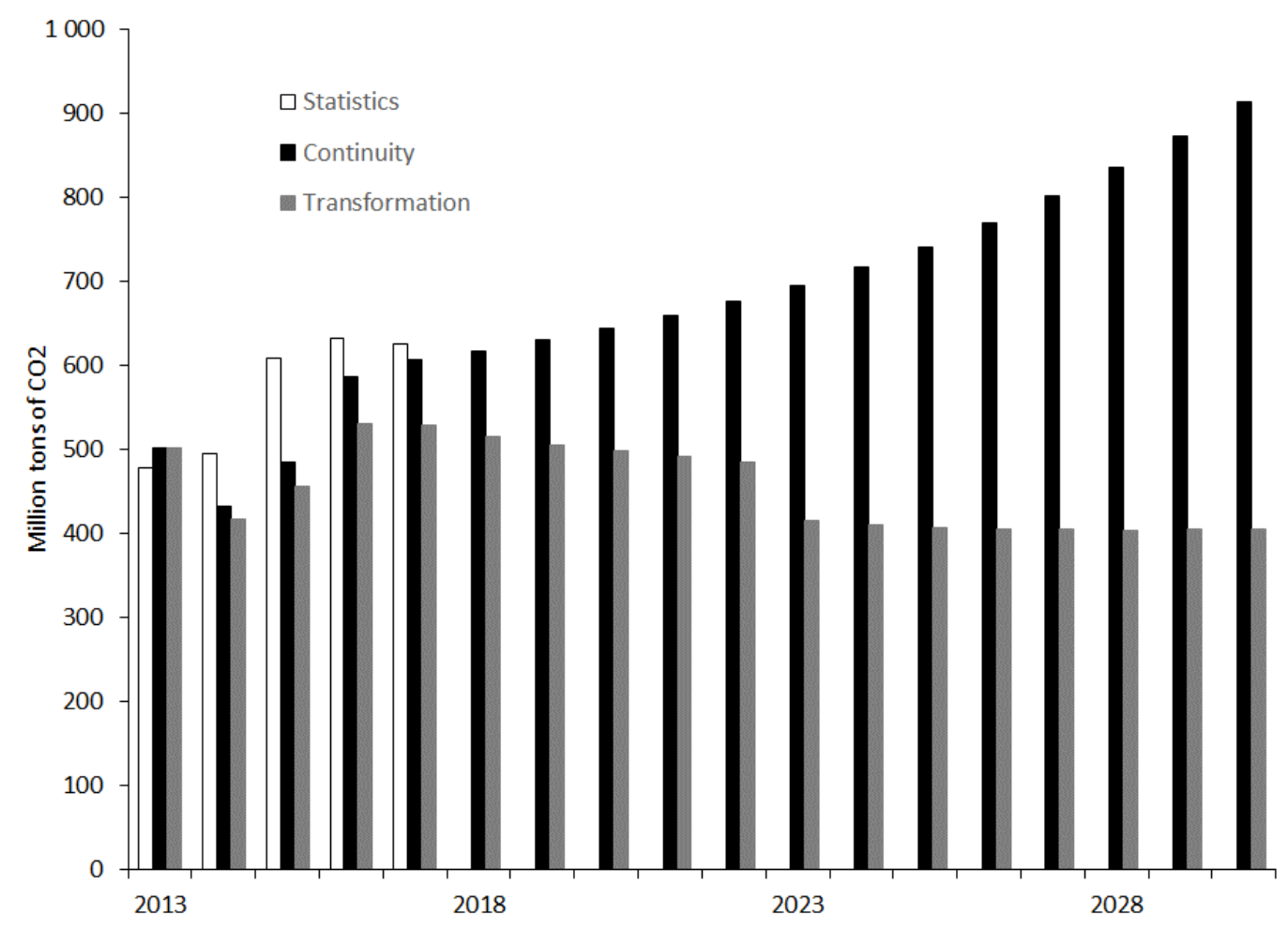

Sources: EDGAR database (https://edgar.jrc.ec.europa.eu) for 2013-2017 statistics and IMACLIM-SAU simulations.

\section{CONCLUSION AND POLICY IMPLICATION}

In this paper, we investigate the impact of diversification strategies of the Kingdom of Saudi Arabia (KSA) in response to rapid global climate action inducing depressed oil prices. To do so, we extend the work of Soummane et al. (2019) into a multi-sectoral framework with explicit representation of the secondary distribution of income and consecutive debt accumulation. 
Over its projection horizon to 2030, our numerical modeling associates the diversification strategy of Transformation toward non-energy-intensive sectors and fiscal reforms with higher growth and lower unemployment than Continuity of expansion of energy-intensive industries. By structural change and through reforming energy prices, Transformation succeeds in containing domestic energy consumptions, whereas Continuity inflates them significantly beyond real economic growth. Also, the energy-price increases of Transformation induce partial decarbonization of energy supply that roughly leads to stabilization of $\mathrm{Saudi}_{\mathrm{CO}}$ emissions from 2023 on, at a level significantly below that of 2013 and largely below that of Continuity emissions.

Lastly, through cuts in energy subsidies and gradual fiscal reforms, Transformation considerably improves public budget outlooks by restoring surpluses from 2025 on. In this regard, Continuity proves a dead-end by failing to hedge against the IEA-projected 2025 downturn of the international price of oil associated with its Sustainable Development Scenario's global peak in oil demand, thus inducing substantial public deficits and the consecutive accumulation of a net public debt ultimately jeopardizing the Saudi growth model. ${ }^{10}$

However, our Transformation scenario rests on export impulses fostering activity shifts and on generalized reforms of the energy sector and taxation system, whose enabling conditions require further investigation. The take-off of non-oil trade demands increasing the productivity and competitiveness of the Saudi private sector, which has been a hurdle to past diversification plans. Export-oriented services and industries rely on the capacity of the authorities to channel investment towards high value-added branches, in which the KSA could benefit from comparative advantages (e.g., geographical location, size of the domestic market, regional leadership). For the manufacturing industries, the KSA could rely on technology transfer and integration with its regional market. Energy efficiency gains not only lessen the impacts of energy-pricing reforms on the costs of producers and the budgets of households, but also free up additional refined-products export capacity. Efficiency programs must focus on waste reduction and demand-side management to limit necessary investments, thus reaching efficiency objectives at least cost.

\footnotetext{
10 The unfolding COVID-19 crisis could accelerate this 2025 tipping point and the compared desirability of the Transformation option. The crisis is too recent to be reflected in our analyses: at the time of writing, there is strong uncertainty on its immediate consequences and repercussions in further years, including on oil markets.
} 
Finally, IMACLIM-SAU surmises perfect labor mobility across sectors, which contradicts the rigidity of the Saudi labor market resulting from its high level of regulation, notably on foreign workers. Similarly, ripping the benefits of Transformation calls for an improvement of education and training programs to meet its skill requirements, especially for Saudi nationals. Indeed, Vision 2030 highlights the necessity of aligning the educational system with future market needs and Saudi authorities launched the National Labor Gateway (TAQAT), which aims at determining the skills and knowledge required by each socio-economic sector (Saudi Arabia, 2016b).

\section{DECLARATION OF COMPETING INTERESTS}

The authors declare that they have no known competing financial interests or personal relationships that could have appeared to influence the work reported in this paper.

\section{ACKNOWLEDGMENTS}

We are grateful to anonymous referees for their comments and suggestions that have helped to considerably improve the paper; nonetheless, we are, of course, responsible for all errors and omissions. Development and implementation of IMACLIM-SAU was part of the Ph.D. research of Salaheddine Soummane funded by the French EDF R\&D company under the ANRT convention CIFRE2015/1313. We thank the King Abdullah Petroleum Studies and Research Center (KAPSARC) in the persons of Walid Matar and Hossa Almutairi for kindly providing results of KEM simulations, complementary data for this study, and comments on an earlier draft. The continuous development of the IMACLIM model benefits from the support of the Chair Long-Term Modeling for Sustainable Development (Ponts Paristech-Mines Paristech) funded by Ademe, GRT-Gaz, Schneider Electric, EDF, RTE, Total, and the French Ministry of Environment.

\section{REFERENCES}

Al Yousif, M., and A. Al Bakr (2017). Tourism development effect on saudi economic diversification. SAMA Working Paper, March 2017. http://www.sama.gov.sa/en-

US/EconomicResearch/WorkingPapers/Tourism\%20Development\%20Effect\%200n\%20Saudi\%20Economic\%20 Diversification.pdf.

Albassam, B. A. (2015). “Economic diversification in Saudi Arabia: Myth or reality?" Resources Policy 44, 112117. https://doi.org/10.1016/j.resourpol.2015.02.005. 
Al-Hawwas, A. (2010). "Policy experiments for the Saudi's economy using a Computable General Equilibrium Model (CGE), oil demand and tariff liberalization effects on the Saudi economy". PhD thesis, University of Dundee, Dundee, United Kingdom. https://discovery.dundee.ac.uk/files/1692405/Al-Hawwas_phd_2010.pdf

AlKathiri, N., T.N. Atalla, F. Murphy, and A. Pierru (2020). “Optimal policies for managing oil revenue stabilization funds: An illustration using Saudi Arabia”. Resources Policy, 67, 101686.

https://doi.org/10.1016/j.resourpol.2020.101686

Al-Thumairi, I. A. (2012). "Fixed or flexible exchange rate for Saudi Arabia: optimal solution of CGE model". International Journal of Basic and Applied Sciences 1 (2), 67-87.

http://citeseerx.ist.psu.edu/viewdoc/download?doi=10.1.1.1004.12\&rep=rep1\&type=pdf.

Bauer, N., I. Mouratiadou, G. Luderer, L. Baumstark, R. J. Brecha, O. Edenhofer, and E. Kriegler, (2013). “Global Fossil Energy Markets and Climate Change Mitigation: An Analysis with REMIND". Climatic Change, 136(1), 6982. https://doi.org/10.1007/s10584-013-0901-6.

Blanchflower, D. G. and A. J. Oswald (2005). "The wage curve reloaded". National Bureau of Economic Research no. w11338. https://www.nber.org/papers/w11338.pdf.

Blazquez, J., L.C. Hunt, and B. Manzano (2017). “Oil Subsidies and Renewable Energy in Saudi Arabia: A General Equilibrium Approach.” The Energy Journal 38(SP1): 29-45. https://doi.org/10.5547/01956574.38.SI1.jbla.

Callen, M. T., R. Cherif, F. Hasanov, M.A. Hegazy, and P. Khandelwal (2014). Economic diversification in the GCC: Past, present, and future. International Monetary Fund.

https://www.imf.org/ /media/Websites/IMF/Imported/external/pubs/ft/sdn/2014/_sdn1412pdf.ashx.

CDSI (2014). National accounts 1435/1436 A.H. (2014). Central Department of Statistics and Information. The Kingdom of Saudi Arabia.

Combet, E., Ghersi, F., Lefèvre, J., Le Treut, G. (2014). Construction of hybrid Input-Output tables for E3 CGE model calibration and consequences on energy policy analysis. GTAP resource \#4524, Global Trade Analysis Program, Purdue University, 27 p. https://www.gtap.agecon.purdue.edu/resources/download/6988.pdf.

Crassous, R., J. C. Hourcade, and O. Sassi (2006). “Endogenous Structural Change and Climate Targets. Modeling experiments with IMACLIM-R." The Energy Journal Special Issue, Endogenous Technological Change and the Economics of Atmospheric Stabilization: 259-276. https://doi.org/10.5547/ISSN0195-6574-EJ-VolSI2006-NoSI113.

De Lauretis, S., F. Ghersi, and J. M. Cayla (2017). "Energy consumption and activity patterns: an analysis extended to total time and energy use for French households." Applied Energy 206: 634-648.

https://doi.org/10.1016/j.apenergy.2017.08.180.

De Santis, R. A. (2003). “Crude oil price fluctuations and Saudi Arabia's behavior”. Energy Economics 25 (2), $155-$ 173. https://doi.org/10.1016/S0140-9883(02)00106-8.

Devaux, P. (2013) "Economic diversification in the GCC: dynamic drive needs to be confirmed" BNP Paribas economic research, July-August 2013. http://economic-

research.bnpparibas.com/Views/DisplayPublication.aspx?type=document $\& / \mathrm{dPdf}=22570$.

Edenhofer, O., R. Pichs-Madruga, Y. Sokona, J.C. Minx, E. Farahani, K. Susanne, et al. (2014). “Climate change 2014: mitigation of climate change". https://doi.org/10.1017/СBO9781107415416.

El Mallakh, R. (2015). "Saudi Arabia: Rush to Development (RLE Economy of Middle East): Profile of an energy economy and investment". Routledge. https://doi.org/10.4324/9781315744414.

Ghersi, F. (2015). “Hybrid Bottom-up/Top-down Energy and Economy Outlooks: A Review of IMACLIM-S Experiments". Frontiers in Environmental Science 3 (74), 1-18. https://doi.org/10.3389/fenvs.2015.00074. 
Ghersi, F. and J.C. Hourcade (2006). "Macroeconomic consistency issues in E3 modeling: the continued fable of the elephant and the rabbit". The Energy Journal, Hybrid Modeling, Special Issue \#2, 39-61.

https://doi.org/10.5547/ISSN0195-6574-EJ-VolSI2006-NoSI2-3.

Gonand, F., F. Hasanov and L. Hunt (2019) "Estimating the impact of energy price reform on Saudi Arabian intergenerational welfare using the MEGIR-SA model." The Energy Journal 40(3) pp. 101-123.

https://doi.org/10.5547/01956574.40.3.fgon.

Gupta, D., F. Ghersi, S. S. Vishwanathan, and A. Garg (2019). “Achieving sustainable development in India along low carbon pathways: Macroeconomic assessment". World Development, 123, 104623.

https://doi.org/10.1016/j.worlddev.2019.104623.

Gupta, D., F. Ghersi, S. S. Vishwanathan, and A. Garg (2020). Macroeconomic assessment of India's development and mitigation pathways. Climate Policy 20 (7), 779-799.

https://doi.org/10.1080/14693062.2019.1648235

Hourcade, J. C., M. Jaccard, C. Bataille, and F. Ghersi (2006). “Hybrid Modeling: New Answers to Old Challenges". The Energy Journal Special Issue Hybrid Modeling \#2, 1-11. https://doi.org/10.5547/ISSN01956574-EJ-VolSI2006-NoSI2-1.

Combet, E., F. Ghersi, J.C. Hourcade, D. Théry (2010). "Carbon tax and equity: The importance of policy design". C. Dias Soares, J. Milne, H. Ashiabor, K. Deketelaere, L. Kreiser (Eds.), Critical Issues in Environmental Taxation, Vol. VIII (2010), pp. 277-295

HSBC (2018). "Now, next and how for business. Saudi Arabia report". https://www.business.hsbc.com//media/cmb/tfr/saudi-arabia-report-2018.pdf.

Hvidt, M. (2013) "Economic diversification in GCC countries: Past record and future trends." Research Paper No. 27: Kuwait Programme on Development, Governance and Globalisation in the Gulf States, London School of Economics and Political Science (LSE). http://eprints.Ise.ac.uk/55252/.

IEA (2017). World Energy Outlook 2017. International Energy Agency, Paris, France.

IEA (2019). CO2 Emissions from Fuel Combustion. International Energy Agency, Paris, France.

IMF (2016a). Economic Diversification in Oil-Exporting Arab Countries. In Annual Meeting of Arab Ministers of Finance, April 2016, Manama, Bahrain. International Monetary Fund.

https://www.imf.org/external/np/pp/eng/2016/042916.pdf.

IMF (2016b). World Economic Outlook Database, April 2016. International Monetary Fund, Washington, D.C. https://www.imf.org/external/pubs/ft/weo/2016/01/weodata/index.aspx.

Jadwa (2017). "Petrochemicals and the Vision 2030". February 2017.

http://www.jadwa.com/en/download/petrochemicals-and-the-vision-2030/research-13-1-1-1-1-1-1.

Johansson, D.J., C. Azar, K. Lindgren, and T.A. Persson (2009). “OPEC strategies and oil rent in a climate conscious world”. The Energy Journal 30(3) pp. 23-50. https://doi.org/10.5547/ISSN0195-6574-EJ-Vol30-No3-2.

Le Treut, G., (2017). Methodological proposals for hybrid modelling: consequences for climate policy analysis in an open economy (France). https://hal.archives-ouvertes.fr/tel-01707559/document.

Lefèvre, J., W. Wills, and J. C. Hourcade (2018). "Combining low-carbon economic development and oil exploration in Brazil? An energy-economy assessment." Climate policy 18.10 (2018): 1286-1295.

https://doi.org/10.1080/14693062.2018.1431198. 
MGI (2015). "Saudi Arabia beyond oil: the investment and productivity transformation". McKinsey Global Institute, McKinsey \& Company, December 2015. https://www.mckinsey.com/featured-insights/employmentand-growth/moving-saudi-arabias-economy-beyond-oil.

Moya, J.A. and A. Boulamanti, A. (2016). "Production costs from energy-intensive industries in the EU and third countries". EUR27729EN; doi:10.2790/056120. https://core.ac.uk/download/pdf/38632391.pdf.

Pershing, J., (2000). "Fossil fuel implications of climate change mitigation responses".

LJ. Berstein, J. Pan (Eds.), Sectoral Economic Costs and Benefits of Greenhouse Gas Mitigation, IPCC, Bilthoven, the Netherlands. https://archive.ipcc.ch/pdf/supporting-material/sectoral-economic-costs-2000.pdf.

Persson, T. A., C. Azar, D. Johansson, and K. Lindgren (2007). "Major oil exporters may profit rather than lose, in a carbon-constrained world". Energy Policy, 35(12), 6346-6353. https://doi.org/10.1016/j.enpol.2007.06.027.

Rutherford, T. F. (1999). “Applied general equilibrium modeling with MPSGE as a GAMS subsystem: An overview of the modeling framework and syntax". Computational economics, 14(1-2), 1-46.

https://doi.org/10.1023/A:1008655831209.

Sassi, O., R. Crassous, J. C. Hourcade, V. Gitz, H. Waisman, and C. Guivarch (2010). "Imaclim-R: a modelling framework to simulate sustainable development pathways". International Journal of Global Environmental Issues, 10: 5-24. https://doi.org/10.1504/IJGENVI.2010.030566.

Saudi Arabia (2005). "First National Communication of the Kingdom of Saudi Arabia to the UNFCCC". https://unfccc.int/resource/docs/natc/saunc1.pdf.

Saudi Arabia (2011). "Second National Communication of the Kingdom of Saudi Arabia to the UNFCCC". https://unfccc.int/resource/docs/natc/saunc2.pdf.

Saudi Arabia (2015). "The Intended Nationally Determined Contribution of the Kingdom of Saudi Arabia under the UNFCCC". https://www4.unfccc.int/sites/ndcstaging/PublishedDocuments/Saudi\%20Arabia\%20First/KSAINDCs\%20English.pdf.

Saudi Arabia (2016a). "Third National Communication of the Kingdom of Saudi Arabia to the UNFCCC". https://unfccc.int/files/national_reports/non-

annex_i_natcom/application/pdf/saudi_arabia_nc3_22_dec_2016.pdf.

Saudi Arabia (2016b). "Saudi Vision 2030".

https://www.vision2030.gov.sa/media/rc0b5oy1/saudi_vision203.pdf.

SAMA (2018). “Annual Statistics 2018”. Saudi Arabian Monetary Authority. Retrieved from http://www.sama.gov.sa/en-US/EconomicReports/Pages/YearlyStatistics.aspx.

Schers, J., F. Ghersi, F. Lecocq, and F. Grazi (2015). “Green Growth and its Implications for Public Policy-The Case of South Africa". https://www.afd.fr/en/green-growth-and-its-implications-public-policy.

Shehabi, M. (2020). "Diversification effects of energy subsidy reform in oil exporters: Illustrations from Kuwait". Energy Policy, 138, 110966. https://doi.org/10.1016/j.enpol.2019.110966.

Soummane, S. and F. Ghersi (2019). "Hybrid Input-Output tables for Saudi Arabia at the year 2013", Mendeley Data, V2. https://doi.org/10.17632/wr9mprpj5k.2.

Soummane, S. and F. Ghersi (2020). "The IMACLIM-SAU model version 1.0", CIRED Working Paper 2020-77, CIRED, Paris. http://www.centre-cired.fr/wp-

content/uploads/2020/11/cired_wp_2020_77_soummane_ghersi.pdf. 
Soummane, S., F. Ghersi and J. Lefèvre (2019). "Macroeconomic pathways of the Saudi economy: The challenge of global mitigation action versus the opportunity of national energy reforms". Energy Policy, 130, $263-282$. https://doi.org/10.1016/j.enpol.2019.03.062.

Taylor, L. and F. J. Lysy (1979). "Vanishing income redistributions - Keynesian Clues about model surprises in the short run". Journal of Development Economics 6, 11-29. https://doi.org/10.1016/0304-3878(79)90033-6.

Tax Foundation (2018). Corporate Tax Rates Around the World, 2018. Retrieved from: https://taxfoundation.org/corporate-tax-rates-around-world-2018/.

Van de Graaf, T. and A. Verbruggen (2015). "The oil endgame: Strategies of oil exporters in a carbonconstrained world”. Environmental Science \& Policy 54, 456-562. https://doi.org/10.1016/j.envsci.2015.08.004.

Waisman H., J. Rozenberg, and J.C. Hourcade (2013). “Monetary compensations in climate policy through the lens of a general equilibrium assessment: The case of oil-exporting countries". Energy Policy 63, 951-961. https://doi.org/10.1016/j.enpol.2013.08.055. 


\title{
ONLINE APPENDIX TO
}

\section{Structural Transformation Options of the Saudi Economy Under Constraint of Depressed World Oil Prices}

\author{
Salaheddine Soummane ${ }^{a}$, Frédéric Ghersi ${ }^{\mathrm{b}}$, Franck Lecocq ${ }^{\mathrm{c}}$
}

\section{Annex A IMACLIM-SAU FORMULARY}

IMACLIM-SAU operates in a dynamic recursive framework where yearly economy-wide equilibria are connected by accumulation of the capital stock, financial debts and chained price indexes. From a mathematical point of view, each yearly equilibrium results from the solving of a system of simultaneous non-linear equations:

$$
\left\{\begin{array}{c}
f_{1}\left(x_{1}, x_{2} \ldots, x_{n}, y_{1}, y_{2} \ldots, y_{m}\right)=0 \\
f_{2}\left(x_{1}, x_{2} \ldots, x_{n}, y_{1}, y_{2} \ldots, y_{m}\right)=0 \\
\ldots \\
f_{n}\left(x_{1}, x_{2} \ldots, x_{n}, y_{1}, y_{2} \ldots, y_{m}\right)=0
\end{array}\right.
$$

With $x_{i}$ a set of $n$ variables, $y_{i}$ a set of $m$ parameters and $f_{i}$ a set of $n$ functions, for some of them linear, for some of them non-linear, in $x_{i}$. The $f_{i}$ functions embody constraints of either an accounting nature or a behavioral nature. The accounting constraints impose themselves on the modeler for the sake of consistency. The behavioral constraints, quite distinctively, convey the modeler's views on economic causalities and correlations.

\footnotetext{
${ }^{a}$ Corresponding author. CIRED, AgroParisTech, CIRAD, CNRS, EHESS, Ecole des Ponts ParisTech, Univ Paris-Saclay, UMR 8568. CIRED, 94736 Nogent-sur-Marne, France. E-mail: salaheddine.soummane@kapsarc.org.

${ }^{b}$ CIRED, AgroParisTech, CIRAD, CNRS, EHESS, Ecole des Ponts ParisTech, Univ Paris-Saclay, UMR 8568. CIRED, 94736 Nogent-sur-Marne, France. E-mail: ghersi@centre-cired.fr.

' CIRED, AgroParisTech, CIRAD, CNRS, EHESS, Ecole des Ponts ParisTech, Univ Paris-Saclay, UMR 8568. CIRED, 94736 Nogent-sur-Marne, France. E-mail: lecocq@centre-cired.fr.
} 
The count of equations and variables depends on whether IMACLIM-SAU models regulated energy prices or not. Regulated versus reformed energy prices affect equations (32), (57) and (58), which shift from (a) to (b) variants. Because of indexed notation, each equation covers up to 169 constraints (the intermediate prices of 13 products into 13 productions). The detail is as follows:

- Equations (4), (7), (8), (10), (11), (12), (14), (15), (16), (17), (18), (19), (20), (21), (23), (24), (25), (26), (27), (28), (31), (32) (a or b), (33), (34), (37), (40), (42), (43), (45), (47), (60), and (61) cover one constraint each: 32 constraints.

- $\quad$ Equation (58b) covers 2 constraints.

- Equations (9), (50), (58a) and (59) cover 4 constraints each: 16 constraints in the regulated (a) variant, 12 constraints in the reformed (b) variant.

- Equation (13) covers 8 constraints.

- $\quad$ Equations (1), (2), (3), (29), (30), (48) cover 9 constraints each (for 9 non-energy goods): 54 constraints.

- Equations (5), (6), (22), (35), (36), (38), (39), (41), (44), (46), (49), (51), (53), (54), (55) and (56), cover 13 constraints each (one equation per sector): 208 constraints.

- $\quad$ Equation (57b) covers 26 constraints.

- $\quad$ Equation (57a) covers 52 constraints.

- Equation (52) covers 169 constraints (input-output prices).

The version considering regulated energy prices (a variants) thus counts 539 constraints, while that considering reformed prices (b variants) counts 511 constraints. The following table identifies the 539/511 variables (Var. count of last-but-one column) matching these numbers of constraints with, when differentiated, the count of the regulated model on the left side and that of the reformed model on the right side of a slash sign. The table also lists all parameters of the model, which for most of them are calibrated at base-year level on our hybrid dataset, for some others stem from other external sources.

\section{Table A.1: IMACLIM-SAU notations}

\begin{tabular}{lllc}
\hline \hline Notation & Description & Var. & Par. \\
\hline$C_{i}$ & Final consumption of good $i$ by households. Consumptions of energy goods are exogenous (see & 8 \\
& Annex C.2). Consumption of $A G R$ is exogenous as well (follows population dynamics). & 5 \\
$D_{j}$ & Net debt of agent $j \in\{H, F, G, R O W\}$ (households, firms, public administrations, foreign agents). & 4 \\
$G F C F_{j}$ & Gross fixed capital formation of agent $j \in\{H, F, G\}$ (households, firms, public administrations). & 0 \\
$G_{i}$ & Final public consumption of good $i$. & 0 & 0
\end{tabular}




\begin{tabular}{|c|c|c|}
\hline$I_{i}$ & Final consumption of good $i$ in investment. & 13 \\
\hline$K_{i}$ & Total capital stock in sector $i$. & 13 \\
\hline$L_{i}$ & Total labor demand from sector $i$ & 13 \\
\hline$K L_{i}$ & Value-added $K L$ intensity of the production of non-energy good $i$. & 9 \\
\hline$M_{i}$ & $\begin{array}{l}\text { Imports of good } i \text {. Imports of REF are exogenous (Annex C.4), imports of OIL, GAS and ELE are } \\
\text { exogenously set to } 0 \text {. }\end{array}$ & 9 \\
\hline$N L B_{j}$ & $\begin{array}{l}\text { Net lending or borrowing of agent } j \in\{H, F, G, R O W\} \text { (households, firms, public administrations, } \\
\text { foreign agents). }\end{array}$ & 4 \\
\hline$N_{P}$ & Pensioned population & 0 \\
\hline$N_{T}$ & Total population & 0 \\
\hline$N_{U}$ & Unemployed population & 1 \\
\hline$R_{C}$ & Consumption budget of households & 1 \\
\hline$R_{j}$ & Gross disposable income of agent $j \in\{H, F, G\}$ (households, firms, public administrations). & 3 \\
\hline$S_{i}$ & Total supply of good $i$. & 13 \\
\hline$X_{i}$ & $\begin{array}{l}\text { Export of good } i \text {. Exports of GAS and ELE are exogenously set to } 0 \text { in both scenarios. Additionally, } \\
\text { exports of OIL are exogenous in the Transformation scenario (Annex C.4). }\end{array}$ & $11 / 10$ \\
\hline$Y_{i}$ & $\begin{array}{l}\text { Domestic output of good } i \text {. Outputs of OIL and REF are exogenous in the Continuity scenario. Output } \\
\text { of REF alone is exogenous in the Transformation scenario (Annex C.4). }\end{array}$ & $11 / 12$ \\
\hline$a_{K L i}$ & Parameter of substitution of $K$ to $L$ in good $i$ production. & 0 \\
\hline$b_{K L i}$ & Parameter of substitution of $K$ to $L$ in good $i$ production. & 0 \\
\hline$i_{j}$ & Effective interest rate on the net debt of agent $j \in\{H, F, G\}$. & 0 \\
\hline$p_{C i}$ & Price of good $i$ for households. See Annex C.1 for the specific assumptions regarding energy prices. & 13 \\
\hline$p_{G i}$ & Public price of good $i$. & 13 \\
\hline$p_{I i}$ & Investment price of good $i$. & 13 \\
\hline$p_{L i}$ & Cost of labor input in the production of good $i$. & 13 \\
\hline$p_{M i}$ & $\begin{array}{l}\text { Import price of good } i \text {. The import prices of non-energy goods are constant (non-energy imports are } \\
\text { the model's numéraire). See Annex C.3 for the specific assumptions regarding the import prices of } \\
\text { energy. }\end{array}$ & 4 \\
\hline$p_{K L_{i}}$ & Price of value-added good $K L$ in non-energy sector $i$. & 9 \\
\hline$p_{S i}$ & Average price of good $i$ supply (output and imports). & 13 \\
\hline$p_{X i}$ & $\begin{array}{l}\text { Export price of good } i \text {. See Annex C. } 3 \text { for the specific assumptions regarding the export prices of } \\
\text { energy. }\end{array}$ & 13 \\
\hline$p_{Y i}$ & Output price of good $i$. & 13 \\
\hline$p_{i j}$ & $\begin{array}{l}\text { Price of good } i \text { for the production of good } j \text {. See Annex C.1 for the specific assumptions regarding } \\
\text { intermediate energy prices. }\end{array}$ & 169 \\
\hline$s_{I}$ & $\begin{array}{l}\text { Investment effort as a share of GDP. } 2013 \text { to } 2017 \text { efforts are indexed on The World Bank statistics. } \\
\text { From } 2018 \text { on, the ratio linearly converges to its 2013-2017 average in } 2030 \text {. }\end{array}$ & 0 \\
\hline$t_{E T C i}$ & Net energy tax per unit of household consumption of good $i$. & 0 \\
\hline$t_{\text {ETGi }}$ & Net energy tax per unit of public consumption of good $i$. & 0 \\
\hline$t_{E T I i}$ & Net energy tax per unit of good $i$ immobilization. & 0 \\
\hline$t_{\text {ETij }}$ & Net energy tax per good $i$ consumption in good $j$ production. & 0 \\
\hline$t_{\text {отCi }}$ & Net other excise tax per unit of household consumption of good $i$. & 0 \\
\hline$t_{\text {OTG }}$ & Net other excise tax per unit of public consumption of good $i$. & 0 \\
\hline$t_{\text {OTIi }}$ & Net other excise tax per unit of good $i$ immobilization. & 0 \\
\hline$t_{\text {OTij }}$ & Net other excise tax per good $i$ consumption in good $j$ production. & 0 \\
\hline$\alpha_{i j}$ & Technical coefficient, good $i$ intensity of good $j$. & 0 \\
\hline$\delta_{T M}$ & Scaling factor on transport margins of transport-providing sectors. & 1 \\
\hline$\delta_{X i}$ & Scaling factor on good $i$ exports accounting for the growth trend of Saudi export markets. & 0 \\
\hline$\kappa_{i}$ & Technical coefficient, capital (write-off) intensity of good $i$. Exogenous for energy goods. & 9 \\
\hline$\lambda_{i}$ & Technical coefficient, labor intensity of good $i$. Exogenous for energy goods. & 9 \\
\hline$\pi_{i}$ & Rate of net operating surplus (mark-up) in the production of good $i$. & 0 \\
\hline$\rho_{K L i}$ & Parameter of substitution of $K$ to $L$ in good $i$ production. & 0 \\
\hline$\rho_{P}$ & Average per capita pensions benefitting the retired population. & 1 \\
\hline
\end{tabular}



prices.

$\sigma_{X p i} \quad$ Elasticity of the share of exports into total good $i$ uses to the ratio of import to export prices (does not apply to exports of GAS and ELE, exogenously equal to zero).

Elasticity of the purchasing power of wages to the unemployment rate.

Corporate tax rate.

Average annual monetary inflation rate between the calibration year and all projected years.

Income tax rate on households' gross disposable income.

Social contribution (labor tax) rate applicable to wages in sector $i$.

Saving rate of households.

Specific margin on households' consumption of good $i$. In the Continuity scenario, the four margins on energy sales adjust to warrant administered energy prices. In the Transformation scenario, the margins on GAS and OIL adjust to align domestic prices on international prices while the margins on ELE and REF are constant parameters (prices are liberalized).

$\tau_{S M X i} \quad$ Specific margin on good $i$ exports. Margins on energy exports adjust to accommodate exogenous export prices of energy goods.

$\tau_{S M i j} \quad$ Specific margin on good $i$ consumption in good $j$ production. In the Continuity scenario, the margins on sales of all energy goods to all sectors adjust to warrant administered prices. In the Transformation scenario, the margins on GAS and OIL adjust to align domestic prices on international prices while the margins on ELE and REF are constant parameters (prices are liberalized).

Trade margin on the sales of good $i$.

$\tau_{V A T i} \quad$ Value-added tax rate applying to the consumption of good $i$.

$\tau_{Y i} \quad$ Output tax rate on the production of good $i$.

$\omega_{K G i} \quad$ Share of capital income of sector $i$ accruing to public administrations.

$\omega_{K H} \quad$ Share of total capital income accruing to households.

Ratio to GDP of not-elsewhere accounted for transfers accruing to agent $j \in\{H, F, G\}$ (households, 


\section{A.1 Firms}

\section{Producers' trade-offs}

Trade-offs in the production of energy goods $E=\{O I L, G A S, R E F, E L E\}$ are exogenous assumptions based on KEM and IEA data (see Annex C).

Non-energy productions follow a standard nested production tree. At the bottom of the tree, capital and labor trade off with a constant $\sigma_{K L i}$ elasticity of substitution to form the value-added aggregate $K L_{i}$. The mobilized quantity of labor $L_{i}$ is however augmented by a productivity factor $\phi$, while both the labor and capital inputs are also adjusted by dynamic calibration factors $\Omega$ (see Annex B.2). Therefore $K L_{i}=\left(\alpha_{K L i}\left(\Omega_{K} K_{i}\right)^{\rho_{K L i}}+\right.$ $\left.\beta_{K L i}\left(\Omega_{L} \phi L_{i}\right)^{\rho_{K L i}}\right)^{\frac{1}{\rho_{K L i}}}$, with here and elsewhere, for convenience, $\rho_{i}=\frac{\sigma_{i}-1}{\sigma_{i}}$. Facing prices $p_{K}$ and $p_{L i}$, cost minimization induces:

$$
\begin{aligned}
& \forall i \notin E \quad L_{i}=\frac{1}{\Omega_{L} \phi}\left(\frac{\Omega_{L} \phi \beta_{K L_{i}}}{p_{L_{i}}}\right)^{\sigma_{K L_{i}}}\left(\alpha_{K L_{i}}^{\sigma_{K L_{i}}}\left(\frac{p_{K}}{\Omega_{K}}\right)^{1-\sigma_{K L_{i}}}+\beta_{K L_{i}}^{\sigma_{K L_{i}}}\left(\frac{p_{L_{i}}}{\Omega_{L} \phi}\right)^{1-\sigma_{K L_{i}}}\right)^{-\frac{1}{\rho_{K L_{i}}}} K L_{i} \\
& \forall i \notin E \quad K_{i}=\frac{1}{\Omega_{K}}\left(\frac{\Omega_{K} \alpha_{K L_{i}}}{p_{\mathrm{K}}}\right)^{\sigma_{K L i}}\left(\alpha_{K L_{i}}^{\sigma_{K L_{i}}}\left(\frac{p_{\mathrm{K}}}{\Omega_{\mathrm{K}}}\right)^{1-\sigma_{K L_{i}}}+\beta_{K L_{i}}^{\sigma_{K L_{i}}}\left(\frac{p_{L_{i}}}{\Omega_{\mathrm{L}} \phi}\right)^{1-\sigma_{K L_{i}}}\right)^{-\frac{1}{\rho_{K L_{i}}}} K L_{i}
\end{aligned}
$$

All secondary factor intensities are exogenous, taken from either KEM (energy intensities) or constant at calibration-year value (non-energy intensities). The value-added intensity of non-energy productions is constant (Leontief assumption):

$$
\forall i \notin E \quad \frac{K L_{i}}{Y_{i}}=\frac{K L_{i 0}}{Y_{i 0}}
$$

The absence of proper estimates for Saudi substitution elasticities led to borrow these parameters from the literature (Okagawa and Ban, 2008). 
Table A.2: Elasticities of substitution of capital and labor

\begin{tabular}{lr}
\hline \hline Sector & $\sigma_{K L}$ \\
\hline OIL & 0.139 \\
GAS & 0.139 \\
REF & 0.046 \\
ELE & 0.46 \\
AGR & 0.023 \\
MIN & 0.139 \\
CHM & 0.33 \\
NMM & 0.358 \\
MAN & 0.046 \\
WTP & 0.31 \\
ATP & 0.31 \\
OTP & 0.31 \\
C\&S & 0.31 \\
\hline
\end{tabular}

\section{Net lending and borrowing and net financial debt}

The firms' gross disposable income $R_{F}$ consists of the remainder of the Gross Operating Surpluses (GOS) of sectors, taking account of the shares accruing to households and public administrations, and a share $\omega_{\text {OTF }}$ of GDP as residual transfers, minus interest payments on their net financial debt $D_{F}$, at rate $i_{F}$, and corporate taxes at rate $\tau_{C T}$ on their net operating surplus $\sum_{i} \pi_{i} p_{i} Y_{i}$ :

$$
\begin{aligned}
R_{F}= & \sum_{i} G O S_{i}-\sum_{i} \omega_{K G i} G O S_{i}-\omega_{K H} \sum_{i} G O S_{i} \\
& +\omega_{O T F} G D P-i_{F} D_{F}-\tau_{C T} \sum_{i} \pi_{i} p_{i} Y_{i}
\end{aligned}
$$

The share $\omega_{O T F}$, the interest rate $i_{F}$ and the corporate tax rate $\tau_{C T}$ are constant over time at their 2013 calibration values.

The GOS of sector $i$ is the sum of the consumption of fixed capital $p_{K} K_{i}$, the net operating surplus $\pi_{i} p_{i} Y_{i}$ and the specific margins $S M_{i}$ (which do not sum to 0 after the calibration year): 


$$
G O S_{i}=p_{K} K_{i}+\pi_{i} p_{Y_{i}} Y_{i}+S M_{i}
$$

The sum of specific margins on sector $i$ sales is:

$$
S M_{i}=\sum_{j} \tau_{S M i j} p_{S i} \alpha_{i j} Y_{j}+\tau_{S M C_{i}} p_{S i} C_{i}+\tau_{S M X_{i}} p_{S i} X_{i}
$$

The margins on non-hybrid sales (the sales of those goods without satellite accounts on physical flows, in the case of IMACLIM-SAU all non-energy goods) are equal to zero. Additionally, for each hybrid good, the sum of margins on all sales is equal to zero at calibration year, by construction of the IOT.

At projection years, all positive trade and transport margins remain at their calibration values while the negative margins, which correspond to those sectors providing the underlying trade and transport services (in the case of IMACLIM-SAU the C\&S sector for trade and the C\&S, WTP, ATP and OTP sectors for transport), adjust to warrant accounting balances:

$$
\begin{gathered}
\sum_{i} \tau_{C M i} p_{S i}\left(\sum_{j} \alpha_{i j} Y_{j}+C_{i}+G_{i}+I_{i}+X_{i}\right)=0 \\
\sum_{i} \tau_{T M i} p_{S i}\left(\sum_{j} \alpha_{i j} Y_{j}+C_{i}+G_{i}+I_{i}+X_{i}\right)=0 \\
\forall i \in\{C P S, W T P, A T P, O T P\} \quad \tau_{T M i}=\left(1+\delta_{T M}\right) \tau_{T M i 0}
\end{gathered}
$$

The firms' investment effort $G F C F_{F}$ is equal to total investment net of the investment of households and public administrations:

$$
G F C F_{F}=\sum_{i} p_{I_{i}} I_{i}-G F C F_{G}-G F C F_{H}
$$

The net lending or borrowing (NLB) of firms $N L B_{F}$ is the difference between the firms' disposable income and investments:

$$
N L B_{F}=R_{F}-G F C F_{F}
$$


The firms' net financial debt $D_{F}$ evolves according to the accumulated NLBs - the net financial debts of domestic agents are the only dynamic variables other than the capital stock and the chained price indexes. Monetary inflation at annual rate $\tau_{M I}$ degrades the real value of the debt. At date $t$ :

$$
D_{F, t}=\left(1-\tau_{M I}\right) D_{F, t-1}-N L B_{F, t}
$$

\section{A.2 Households}

\section{Consumer trade-offs}

Households' final consumption $C_{i}$ are exogenous for energy goods as well as for agricultural goods AGR. For lack of analysis in the available literature, the remainder of the consumption budget allocates according to the CobbDouglas assumption of constant budget shares:

$$
\begin{gathered}
\forall i \in A=\{M I N, C H M, N M M, M A N, C P S, W T P, A T P, O T P\} \\
\frac{p_{C i} C_{i}}{R_{C}-\sum_{j \notin A} p_{C j} C_{j}}=\frac{p_{C i 0} C_{i 0}}{R_{C 0}-\sum_{j \notin A} p_{C j 0} C_{j 0}}
\end{gathered}
$$

\section{Income, savings, investment, NLB and net debt}

The after-tax gross disposable income of households $R_{H}$ proceeds from primary factor income, social transfers, property income and an aggregate of other secondary transfers.

$$
\begin{gathered}
R_{H}=\sum_{i} w_{i} \lambda_{i} Y_{i}+\omega_{K H} \sum_{i} G O S_{i}+\sum_{i=P, U, T} \rho_{i} N_{i} \\
+\omega_{\text {OTH }} G D P-i_{H} D_{H}-\tau_{I T} R_{H}
\end{gathered}
$$

Primary factor income comprises the sum of net wages from all economic sectors $\sum_{i} w_{i} \lambda_{i} Y_{i}$ and an $\omega_{K H}$ share of gross operating surpluses $G_{O S}$, directly accruing to households in the form of, mainly, housing rents (imputed or real). Social transfers involve pensions $\rho_{P} N_{P}$, unemployment transfers $\rho_{U} N_{U}$ and other social transfers $\rho_{T} N_{T} . \rho_{i}$ stands for per capita transfers and $N_{i}$ for a target population: exogenous pensioned population $N_{P}$, 
endogenous unemployed population $N_{U}$ or exogenous total population $N_{T}$. Other transfers form a constant $\omega_{\text {OTH }}$ share of GDP calibrated at base year. They include international remittances, which reach $4.7 \%$ of GDP in the case of Saudi Arabia at our 2013 calibration year (Al Kaabi, 2016). Property income is the interest payment on the net debt $D_{H}$ at rate $i_{H}$ resulting from the balance of income from financial assets and interest payments on liabilities. Income taxes are paid at rate $\tau_{I T}$ on disposable income $R_{H}$.

Following on our choice of a Johansen closure (see Section 2), Households' savings at rate $\tau_{S}$ adjust to balance investments and savings. The consumption budget of households is equal to the disposable income net of savings:

$$
R_{C}=\left(1-\tau_{S}\right) R_{H}
$$

The investment effort of households $G F C F_{H}$ is indexed on both disposable income $R_{H}$ and the aggregate investment effort $s_{I}$ :

$$
\mathrm{GFCF}_{H}=A_{G F C F H} R_{H} S_{I}
$$

With $A_{G F C F H}$ a constant calibrated on base-year values. The net lending or borrowing of households $N L B_{H}$ is the difference between their disposable income and their consumption and investment:

$$
N L B_{H}=R_{H}-R_{C}-G F C F_{H}
$$

Similar to firms, the net household debt at date $t$ resulting from the accumulation of NLBs is:

$$
D_{H, t}=\left(1-\tau_{M I}\right) D_{H, t-1}-N L B_{H, t}
$$




\section{A.3 Public administrations}

\section{Public income}

The gross disposable income of public administrations $R_{G}$ derives from taxes and social security contributions $T$, exogenous $\omega_{K G i}$ and $\omega_{O T G}$ shares of the GOS of sectors (reflecting public participations) and GDP, corrected from transfers to households $\sum_{j} \rho_{j} N_{j}$ and interest payments at rate $i_{G}$ on the net public debt $D_{G}$ :

$$
R_{G}=T+\sum_{i} \omega_{K G i} G O S_{i}+\omega_{O T G} G D P-\sum_{i=U, P, T} \rho_{i} N_{i}-i_{G} D_{G}
$$

Tax revenue $T$ comprises primary factor and output taxes, value-added and excise taxes, the income tax and other direct taxes, and the corporate tax:

$$
\begin{gathered}
T=\sum_{i=1}^{n} \tau_{L T i} w_{i} \lambda_{i} Y_{i}+\tau_{Y i} p_{Y i} Y_{i}+\frac{\tau_{V A T_{i}}}{1+\tau_{V A T_{i}}}\left(p_{C_{i}} C_{i}+p_{G_{i}} G_{i}+p_{I_{i}} I_{i}\right) \\
+\sum_{i} \sum_{j}\left(t_{E T i j}+t_{\text {OTij }}\right) \alpha_{i j} Y_{j}+\left(t_{E T C i}+t_{O T C i}\right) C_{i}+\left(t_{E T G i}+t_{O T G i}\right) G_{i}+\left(t_{E T I i}+t_{O T I i}\right) I_{i} \\
+\tau_{I T} R_{H}+t_{H} C P I N_{T}+\tau_{C T} \sum_{i} \pi_{i} p_{Y i} Y_{i}
\end{gathered}
$$

\section{Public expenditures and budget balance}

The value of total public consumption is a constant $s_{G}$ ratio to GDP:

$$
\sum_{i} p_{G_{i}} G_{i}=s_{G} G D P
$$

Sectoral public expenses grow homothetically from calibration year:

$$
G_{i}=\beta_{G} A_{G i}
$$

With $A_{G i}$ a set of constants calibrated at base year.

Social transfers per capita, $\rho_{U}, \rho_{P}$ and $\rho_{T}$, are indexed on the average wage:

$$
\rho_{P}=A_{\rho P} w
$$




$$
\begin{gathered}
\rho_{U}=A_{\rho U} w \\
\rho_{T}=A_{\rho T} w
\end{gathered}
$$

With $A_{\rho P}, A_{\rho U}$ and $A_{\rho T}$ three constants calibrated at base year.

Public investment is indexed on total investment. This effectively maintains the public contribution to investment at calibration-year level (37.7\%), which is close to the observed average between 2010 and 2016 (SAMA, 2018) at $36.2 \%$ of total investment.

$$
G F C F_{G}==A_{G F C F G} \sum_{i} p_{I i} I_{i}
$$

With $A_{G F C F G}$ a constant calibrated at base year. Similar to firms or households, the NLB of public administrations is the difference between disposable income and investment:

$$
N L B_{G}=R_{G}-G F C F_{G}
$$

The public debt accumulates as:

$$
D_{G, t}=\left(1-\tau_{M I}\right) D_{G, t-1}-N L B_{G, t}
$$

\section{A.4 International trade and the foreign agent}

For all energy goods, imports are exogenous, and exports are either exogenous as well, or flow from market clearing (see below). For the non-energy goods, the share of imports $M_{i}$ in total resource $S_{i}$ has a $\sigma_{M p_{i}}$ elasticity to terms-of-trade and is corrected by the inverse of the export dynamic calibration factor $\Omega_{B}$ (see Annex B.2):

$$
\forall i \notin\{O I L, G A S, R E F, E L E\} \quad \frac{M_{i}}{s_{i}}=\frac{1}{\Omega_{B}} A_{M_{i}}\left(\frac{p_{Y_{i}}}{p_{M_{i}}}\right)^{\sigma_{M_{p}}}
$$


with $A_{M_{i}}$ constants calibrated on 2013 data. We follow IMF (2016) using elasticities from Hakura and Billmeier (2008) to set $\sigma_{M p}$ at -0.09 for all non-energy sectors indistinctly. We regard this elasticity as compatible with the import structure of the Kingdom, composed of goods with very few domestic substitution opportunities.

Non-energy exports $X_{i}$ are elastic to terms of trade around exogenous trends $\delta_{X i}$ reflecting the growths of Saudi export markets as well as diversification strategies (see Section 3). Like import elasticities, we derive $\sigma_{X_{p}}$ from IMF (2016) based on Hakura and Billmeier (2008) estimating the elasticity of non-oil exports at 0.69:

$$
\forall i \notin\{O I L, G A S, R E F, E L E\} \quad X_{i}=\Omega_{B}\left(1+\delta_{X i}\right) A_{X_{i}}\left(\frac{p_{X_{i}}}{p_{M_{i}}}\right)^{\sigma_{X p}}
$$

They are adjusted by $\Omega_{B}$ following dynamic calibration from 2014 to 2017 (see Section 2.2). $A_{X_{i}}$ are another set of constants calibrated in 2013 . The trade balance $B$ is:

$$
B=\sum_{i} p_{X_{i}} X_{i}-p_{M_{i}} M_{i}
$$

Both the long-lasting peg of the Saudi riyal to the US dollar and the sensitivity of Saudi exports to the world oil price forbid considering that real effective exchange rate (REER) variations balance Saudi trade (see Section 2). Our Continuity scenario rather constrains the REER to reflect the significant statistical relationship between the REER and the trade balance contribution to GDP detected and explained by Soummane et al. (2019). To specify the relationship, we tested several functional forms including a linear link (with an $R^{2}$ of 0.622 ), with little impact on model results. We settle on an exponential form, which exhibits an $R^{2}$ of 0.674 . This relationship defines the REER as an exponential function of the trade-balance-to-GDP ratio:

$$
\frac{C P I}{M P I}=A_{R E E R}+B_{R E E R} e^{C_{R E E R} \frac{B}{G D P}}
$$

with $B_{R E E R}$ and $C_{R E E R}$ calibrated on 1986 to 2015 statistical observation of the two variables (see Figure 1 of Soummane et al., 2019), and $A_{R E E R}$ the adjustment that allows fitting 2013 data.

In our Transformation scenario we drop the constant REER assumption to rather acknowledge the impact of the massive increase of regulated energy prices on the REER by constraining the price of value-added $(K L)$ in the 
C\&S sector on the same $\delta_{p_{K L}}$ trajectory that it follows in our Continuity scenario (implicitly, relative to the numéraire of IMACLIM-SAU i.e. the basket of non-energy foreign goods):

$$
p_{K L_{-} C P S}=\left(1+\delta_{p_{K L}}\right) D_{R E E R}
$$

with $D_{\mathrm{REER}}$ the value of $p_{K L}$ at calibration year.

The Rest of the world (ROW) agent balances out trade (by selling imports $\sum_{i} p_{M i} M_{i}$ and buying exports $\left.\sum_{i} p_{X i} X_{i}\right)$, property income and interest payments. Its net lending or borrowing capacity $N L B_{R O W}$ is thus:

$$
N L B_{R O W}=\sum_{i} p_{M i} M_{i}-\sum_{i} p_{X i} X_{i}-\sum_{j=H, F, G} i_{j} D_{j}-\sum_{j=H, F, G} \omega_{O T j} G D P
$$

The net debt of foreign agents $D_{R O W}$ balances out domestic assets and liabilities:

$$
D_{R O W}=-\sum_{j=H, F, G} D_{j}
$$

\section{A.5 Market clearings}

\section{Goods markets}

The balance of goods markets is between resources, which comprise domestic production $Y_{i}$ and imports $M_{i}$, and uses, which consist of the consumptions of all sectors $\sum_{j} \alpha_{i j} Y_{j}$, households' and public consumptions $C_{i}$ and $G_{i}$, immobilizations $I_{i}$ and exports $X_{i}$. For energy goods, the data hybridization process results in this equation being expressed in thousand tons-of-oil-equivalent (ktoe), in consistency with the 2013 Saudi energy balance of the IEA. The public consumptions and immobilizations of all energy goods are equal to zero at calibration year and remain so up to projection horizons by national accounting convention for the former and by definition for the latter. 


$$
\begin{gathered}
S_{i}=\sum_{j} \alpha_{i j} Y_{j}+C_{i}+G_{i}+I_{i}+X_{i} \\
Y_{i}=S_{i}-M_{i}
\end{gathered}
$$

\section{Labor market}

On the labor market, a 'wage curve' describes the elasticity of real wage (the purchasing power of wage $w$ ) to unemployment $u$. The real wage $w / C P I$ attached to unemployment at 2013 level (5.6\%) is defined as the 2013 average real wage multiplied by labor productivity increase $\phi$ and a wage moderation factor $\Omega_{w}$ (see Annex B.2) via the calibration of one constant $A_{u}$ :

$$
\frac{w}{C P I}=\phi \Omega_{w} A_{u} u^{\sigma_{w u}}
$$

The net wages in all sectors evolve in parallel to $w$ :

$$
w_{i}=A_{w i} w
$$

The cost of labor is equal to the wage increased by labor tax contributions:

$$
p_{L_{i}}=\left(1+\tau_{L T_{i}}\right) w_{i}
$$

Labor demands of all sectors and unemployment balance out labor endowment $L$ :

$$
\sum_{i} L_{i}=(1-u) L
$$

For each sector, labor consumption and output are conventionally related via labor intensity:

$$
L_{i}=\lambda_{i} Y_{i}
$$

The unemployed population $N_{U}$ is:

$$
N_{U}=u L
$$




\section{Capital markets}

On the capital market, sectoral demands balance out capital endowment $K$ :

$$
\sum_{i} K_{i}=K
$$

With for each sector, similarly to labor:

$$
K_{i}=\kappa_{i} Y_{i}
$$

\section{Investment}

Investment expenses $\sum_{i} p_{I_{i}} I_{i}$ form an exogenous share $s_{I}$ of $G D P$ (investment in energy goods is equal to zero except for stock variations that are cancelled out in the data-hybridization process).

$$
\sum_{i} p_{I_{i}} I_{i}=s_{I} G D P
$$

The sectoral structure of investment remains unchanged from the base year to projected horizons:

$$
I_{i}=\beta_{I} A_{I i}
$$

with $A_{I i}$ constants calibrated on 2013 data.

GDP

$G D P$ is defined on the expenditure side as:

$$
G D P=\sum_{i} p_{C_{i}} C_{i}+p_{G_{i}} G_{i}+p_{I_{i}} I_{i}+p_{X_{i}} X_{i}-p_{M_{i}} M_{i}
$$

\section{A.6 Producer and consumer prices}

For non-energy goods, the price of the value-added aggregate $p_{K L_{i}}$ is a canonical function $\left(K L_{i}\right.$ being a CES product of $K_{i}$ and $L_{i}$ ) of prices $p_{K_{i}}$ and $p_{L_{i}}$ and of the elasticity of substitution of the two inputs $\sigma_{K L_{i}}$ : 


$$
p_{K L_{i}}=\left(\alpha_{K L_{i}}^{\sigma_{K L_{i}}}\left(\frac{p_{K_{i}}}{\Omega_{K_{i}}}\right)^{1-\sigma_{K L_{i}}}+\beta_{K L_{i}}^{\sigma_{K L_{i}}}\left(\frac{w_{i}}{\Omega_{L_{i} \phi_{i}}}\right)^{1-\sigma_{K L_{i}}}\right)^{\frac{1}{1-\sigma_{K L_{i}}}}
$$

The output or producer price of goods $i p_{Y_{i}}$ is the sum of input costs, output taxes at a $\tau_{Y i}$ rate, and is subject to a mark-up rate $\pi_{i}$ corresponding to the rent on natural resources and/or the net operating surplus:

$$
p_{Y_{i}}=\sum_{j} p_{j i} \alpha_{j i}+p_{L_{i}} \lambda_{i}+p_{K} \kappa_{i}+\pi_{\mathrm{i}} p_{Y_{i}}+\tau_{Y_{i}} p_{Y_{i}}
$$

The import prices of non-energy goods are exogenous and constant (these goods act as the collective numéraire of the model). The import prices of energy goods follow exogenous trajectories that are indexed on the price of value-added in the C\&S sector, to account for the differentiated impact of oil-price variations on the Saudi and foreign economies (see Annex C.3):

$$
\forall i \in\{O I L, G A S, R E F, E L E\} \quad p_{M i}=A_{p M i} p_{K L_{-} C P S}
$$

With $A_{p M i}$ the ratios of the (year-specific) exogenous international energy prices and the price of value-added in the C\&S sector at base year.

The price $p_{S_{i}}$ of the total resource in good $i, S_{i}$, is inferred from:

$$
p_{S_{i}} S_{i}=p_{Y_{i}} Y_{i}+p_{M_{i}} M_{i}
$$

Turning to purchasers' prices, the price of good $i$ for the production of $\operatorname{good} j, p_{i j}$, is equal to the resource price of good $i$ augmented from commercial margins $\tau_{C M_{i}}$, transport margins $\tau_{T M_{i}}$, agent-specific margins $\tau_{S M_{i j}}$, energy taxes $t_{E T i j}$ and other excise taxes $t_{O T i j}$ : 


$$
p_{i j}=p_{S_{i}}\left(1+\tau_{C M_{i}}+\tau_{T M_{i}}+\tau_{S M_{i j}}\right)+t_{E T i j}+t_{O T i j}
$$

The consumer prices of households, public administrations, the investment good and exports are constructed similarly with additional value-added taxes (except exports) but drop the unnecessary specific margins when energy is not concerned (public consumption, investment):

$$
\begin{gathered}
p_{C_{i}}=\left(p_{S i}\left(1+\tau_{C M_{i}}+\tau_{T M_{i}}+\tau_{S M C_{i}}\right)+t_{E T C i}+t_{\text {OTCi }}\right)\left(1+\tau_{V A T i}\right) \\
p_{G_{i}}=\left(p_{S i}\left(1+\tau_{C M_{i}}+\tau_{T M_{i}}\right)+t_{E T G i}+t_{\text {OTGi }}\right)\left(1+\tau_{V A T i}\right) \\
p_{I_{i}}=\left(p_{S i}\left(1+\tau_{C M_{i}}+\tau_{T M_{i}}\right)+t_{E T I i}+t_{\text {OTIi }}\right)\left(1+\tau_{V A T i}\right) \\
p_{X_{i}}=p_{S i}\left(1+\tau_{C M_{i}}+\tau_{T M_{i}}+\tau_{S M X_{i}}\right)
\end{gathered}
$$

Additionally, the exogenous prices of some energy goods are indexed on the price of value-added in the C\&S sector (by adjustment of specific margins) following Annex C.1.

In scenarios of continued energy-price regulation, e.g. our Continuity scenario of Section 3.1, all domestic energy prices are regulated:

$$
\begin{aligned}
& \forall i \in\{O I L, G A S, R E F, E L E\} \quad p_{i j}=A_{p i j} p_{K L_{-} C P S} \\
& \forall i \in\{O I L, G A S, R E F, E L E\} \quad p_{C i}=A_{p C i} p_{K L_{-} C P S}
\end{aligned}
$$

With $A_{p i j}$ and $A_{p C i}$ parameters computed as the ratios of the (year-specific) regulated energy prices and the price of value-added in the C\&S sector at base year (see Annex C.1).

In scenarios of energy pricing reforms like our Transformation scenario of Section 3.2, only the prices of OIL and GAS are anchored to exogenous assumptions, which shift from the historical low regulated prices to international references (see Annex C.1):

$$
\forall i \in\{O I L, G A S\} \quad p_{i j}=A_{p i j} p_{K L_{-} C P S}
$$


With $A_{p i j}$ and $A_{p C i}$ defined as above. The household prices of OIL and GAS are only set up for the sake of consistency because both underlying consumptions are currently equal to zero and remain so in all scenarios (see Annex C.2).

Irrespective of energy pricing reforms, energy export prices are at exogenous values indexed on the price of value-added in the C\&S sector (see Annex C.3):

$$
\forall i \in\{O I L, G A S, R E F, E L E\} \quad p_{X i}=A_{p X i} p_{K L_{-} C P S}
$$

With $A_{p X i}$ the ratios of the (year-specific) exogenous international energy prices and the price of value-added in the C\&S sector at base year.

The consumer and import price indexes $C P I$ and $M P I$ are computed as chained indexes, i.e. from one period to the next, according to Fisher's formula:

$$
\begin{gathered}
C P I_{t}=C P I_{t-1} \sqrt{\frac{\sum p_{C i, t} C_{i, t-1}}{\sum p_{C i, t-1} C_{i, t-1}} \frac{\sum p_{C i, t} C_{i, t}}{\sum p_{C i, t-1} C_{i, t}}} \\
M P I_{t}=M P I_{t-1} \sqrt{\frac{\sum p_{M i, t} M_{i, t-1}}{\sum p_{M i, t-1} M_{i, t-1}} \frac{\sum p_{M i, t} M_{i, t}}{\sum p_{M i, t-1} M_{i, t}}}
\end{gathered}
$$




\section{Annex B CALIBRATION OF IMACLIM-SAU}

\section{B.1 Secondary distribution of income}

On top of the hybridization of energy flows, ${ }^{4}$ we expand the original CDSI and GSTAT supply-and-use table data by disaggregating total labor costs between labor tax contributions and net labor payments. We base our disaggregation on Saudi legislation regarding insurance contributions. These comprise the social contributions that employers pay for their Saudi employees (we derive the share of Saudi employment from SAMA, 2018), which amount to $10 \%$ of the employee's salary and are due to the General Organization for Social Insurance (GOSI). Also, a $2 \%$ accident insurance for both national and non-national employees, and a $2 \%$ unemployment insurance, which is shared equally between employers and Saudi employees. We also modify CDSI accounts to represent the substantial public subsidy on electricity prices to both activity sectors and households. On the side of expenditures, we split investment among households, public administrations and firms by allocating to households the 'residential building construction' expenses from SAMA (2018); to government, the dedicated series from national accounts (SAMA, 2018); and to firms, the remainder of total investment from the original input-output table.

The additional data required to specify secondary income distribution among households, firms, public administrations and foreign agents (the 'rest-of-the-world' or RoW) are not available from the national accounts of CDSI (2014). We therefore turn to supplementary sources along the following lines.

We distribute the gross operation surplus (GOS) of sectors across the three domestic agents as follows. Firstly, we allocate to households the income from the real estate and renting activities sector of the original IOT of CDSI. Secondly, we assume that public authorities capture:

- $85 \%$ of the GOS from oil and gas extraction activities, corresponding to the upper bound of the prevailing taxation applied by the Saudi government to this branch;

- $71 \%$ of the GOS of the refining sector, corresponding to the share of the public Aramco company in the Saudi refining capacity;

\footnotetext{
${ }^{4}$ Which extends to energy taxes and subsidies (see Soummane et al., 2019).
} 
- $81 \%$ of the GOS of the electricity sector, corresponding to the government's share in Saudi Electricity Company;

- $50 \%$ of the GOS of mineral activities, corresponding to the government's share in the national company Ma'aden;

- And $70 \%$ of the GOS of petrochemical activities, corresponding to the government's share in SABIC.

Firms collect the remainder of the total GOS as indicated by CDSI. The resulting distribution of GOS is of $16.4 \%$ to households, $44.7 \%$ to the government and the remaining $38.9 \%$ to firms.

Concerning direct taxes, corporate taxes apply at a rate of $20 \%$ on profits accruing to shareholders of other nationalities than those of the Gulf Cooperation Council (GCC). For GCC shareholders (including Saudi ones), there is a $2.5 \%$ zakat on profits. Although we already isolate energy-related activities, it remains challenging to distinguish activities attributable to non-GCC investors. Consequently, we retain only the $2.5 \%$ Zakat rate to compute corporate tax payments accruing to the government. Turning to households, there is currently no income tax in force in Saudi Arabia. However, there is a 2.5\% Zakat tax, which we apply to households' disposable income.

Concerning social transfers, we calibrate unemployment transfers from public administrations to households on governmental aid in the framework of the 'Hafiz' program from the Human Resource Development Fund. We assume that the 1.11 million job seekers reported by SAMA (2018) for the year 2013 perceived the monthly financial aid of SAR 2,000. Similarly, we equate total pension disbursements from public administrations to households to the sum of pension payments and compensations to civilian and military personnel from SAMA (2018), which reflects data from the Public Pension Agency. For the remainder of social transfers, we consider total transfers from central government reported by Oxford Economics, to which we subtract the above explicit transfers.

Property incomes of the three domestic agents correspond to interest payments (or revenues) on net debt positions (which evolve with the accumulation of net lending or borrowing positions) and thus require specifying interest rates $i$, which we assume at $5 \%$ for firms and households. Then, the property income is calculated as follows: (i) for households and firms it corresponds to the product of the debt level (see below for calculation) and the interest rate; (ii) for public administration, we use the government's 'other revenue' figures from SAMA 
for the year 2013 , to which we subtract $81 \%$ of the ELE operating surplus, the perceived income tax and other taxes. The computed public property income yields an apparent interest rate of $1.3 \%$. The property income of the RoW balances out the sum of domestic property incomes.

We calibrate the net public debt position at our 2013 base year as the sum of the reserve assets reported by SAMA (2018), comprised of investment in foreign securities (71.6\%), foreign currency and deposits abroad (26.3\%), Special Drawing Rights (1.3\%), and reserve position at the IMF (0.7\%); net of the total public debt, amounting to $2.1 \%$ of GDP during that year. The households' debt for the year 2013 corresponds to the difference between outstanding personal loans, net of assets of investment funds, bank deposits and quasimonetary (assuming a share of $70 \%$ for personal purpose), and bank claims. The ROW debt corresponds to the net international investment position from the balance of payments (BoP) minus gold reserves (SAMA, 2018). The firms' debt balances the total debt of agents.

Finally, we compute an aggregate of remaining 'other transfers' as follows. For households, we use the series of 'Personal transfers', corresponding to workers' remittances, from the Saudi BoP (SAMA, 2018). For public administration, we compute 'other transfers' as the difference between the aggregate budget balance and all resources and expenditures elsewhere accounted for. For the rest of the world, we sum up the opposite of workers' remittances and other net current transfers (i.e., credit minus debit) from the BoP and the governments' secondary income from the BoP. The firms' 'other transfers' simply balance out the 'other transfers' of the other three agents.

\section{B.2 Calibration on 2014 to 2017 macroeconomics}

Dynamic calibration of IMACLIM-SAU on years 2014 to 2017 targets the main macroeconomic indicators of GDP, the unemployment rate and the trade balance-see Annex D.2 of Soummane et al. (2019) for the detailed procedure. Adjustment factors impacting capital productivity $\left(\Omega_{K}\right)$, labor productivity $\left(\Omega_{L}\right)$, the equilibrium wage $\left(\Omega_{w}\right)$ and exports and imports $\left(\Omega_{B}\right)$ are assumed to converge to their 2014-to-2017 averages by 2030 . The resulting factors remain within $7.5 \%$ of their 2013 values for those that concern labor, capital, and real wage expectations. They reach $26.4 \%$ for the non-energy trade factor $\Omega_{B}$, which reflects the fact that non-energy 
trade, although dwarfed by oil trade, must compensate any statistical discrepancy between our sources for the oil price and exports on one side (IEA data), and the aggregate trade balance contribution to GDP on the other side (World Bank data).

Table B.1: Adjustment factors resulting from 2014-to-2017 calibration

\begin{tabular}{lllllllll}
\hline & 2014 & 2015 & 2016 & 2017 & 2020 & 2025 & 2030 \\
\hline$\Omega_{K}$ & 0.964 & 0.962 & 1.003 & 0.975 & 0.976 & 0.978 & 0.981 \\
$\Omega_{L}$ & 1.011 & 1.027 & 1.075 & 1.065 & 1.058 & 1.047 & 1.036 \\
$\Omega_{w}$ & 1.005 & 1.011 & 1.021 & 1.023 & 1.020 & 1.016 & 1.012 \\
$\Omega_{B}$ & 0.736 & 0.790 & 1.012 & 1.104 & 1.061 & 0.992 & 0.928 \\
\hline
\end{tabular}

Note: Calibrated values appear in bold script, projections to 2030 for selected years in light script. 


\section{Annex C ENERGY SCENARIOS}

Parameterization of the energy consumptions and costs constraining IMACLIM-SAU projections are a combination of outputs from the Riyadh-based KAPSARC Energy Model (KEM) and complementary exogenous sources available for the KSA or the broader Middle East region. The hybrid nature of IMACLIM-SAU calibration data warrants the consistent combination of assumptions.

\section{C.1 Domestic energy prices}

After a long period of stagnation of regulated energy tariffs, Saudi Arabia recently engaged in a wide reform of energy pricing (APICORP, 2018). In 2016, the first phase of the reform increased natural gas tariffs by $67 \%$, the price of ethane by $133 \%$, and that of refined products (depending on fuel grade) between $50 \%$ and $79 \%$. In 2018 , the second phase of the reform targeted households' consumptions. It further increased the price of gasoline between $83 \%$ and $127 \%$ (depending on fuel grade) and that of residential electricity by $260 \%$ (for consumptions lower than 6,000 kWh per month).

Our Continuity scenario builds on the assumption that domestic tariffs remain constant in Saudi Riyals after the two pricing reforms of 2016 and 2018, up to 2030 (Table C.1). Because international non-energy goods act as the collective numéraire of IMACLIM-SAU (all their relative prices are fixed across time for all scenarios), and to take account of the differentiated impact of oil price variations on inflation in Saudi Arabia and abroad, particularly in the US, we follow Soummane et al. (2019, see Annex B.2) by indexing the forced exogenous tariffs on the price of value-added in the C\&S sector (see Equations 57 and 58).

However, Saudi authorities are planning further reforms (IMF, 2016; Jadwa, 2018), although they have not communicated target prices. Indeed, energy-pricing reforms are implemented in other Gulf countries, and have accelerated after the sharp decline of the price of oil in 2015 to contain the consecutive massive budget deficits. Saudi plans may extend to raising energy prices to international levels, as ongoing reforms in Qatar and United Arab Emirates suggest (Krane and Shih, 2016). Our Transformation scenario reflects such assumptions. It assumes that domestic oil and gas prices (e.g., for power generation or water desalination) converge with international prices by 2030. Domestic oil prices consequently rise from 6.35 USD per barrel in 2017 to 69 USD 
per barrel in 2030, and domestic natural gas prices from 1.25 USD per million British thermal unit (MBtu) to around 4 USD MBtu (in constant 2016 dollars). These reforms annihilate opportunity costs (the national oil company becomes indifferent between selling oil domestically or abroad) and foster efficiency gains.

Table C.1: Assumptions on domestic oil and gas prices

\begin{tabular}{|c|c|c|c|c|c|}
\hline \multirow{2}{*}{$\begin{array}{l}\text { In SAR/ton-of-oil } \\
\text { equivalent }\end{array}$} & \multirow{2}{*}{$\begin{array}{r}\text { Calibration } \\
2013\end{array}$} & \multicolumn{2}{|c|}{------Continuity------ } & \multicolumn{2}{|c|}{------Transformation------ } \\
\hline & & 2030 & AAGR & 2030 & AAGR \\
\hline$p_{O I L_{-} R E F}$ & 116.5 & 152.7 & $+1.6 \%$ & $2,108.7$ & $+18.6 \%$ \\
\hline$p_{O I L_{-} E L E}$ & 108.6 & 131.5 & $+1.1 \%$ & $1,832.1$ & $+18.1 \%$ \\
\hline$p_{O I L \_N M M}$ & 116.5 & 152.7 & $+1.6 \%$ & $2,108.7$ & $+18.6 \%$ \\
\hline$p_{\text {OIL_MAN }}$ & 116.5 & 152.7 & $+1.6 \%$ & $1,965.5$ & $+18.1 \%$ \\
\hline$p_{G A S_{-} E L E}$ & 111.6 & 163.5 & $+2.3 \%$ & 630.9 & $+10.7 \%$ \\
\hline$p_{G A S \_M I N}$ & 111.6 & 163.4 & $+2.3 \%$ & 630.9 & $+10.7 \%$ \\
\hline$p_{\text {GAS_CHM }_{-}}$ & 111.6 & 199.5 & $+3.5 \%$ & 767.2 & $+12.0 \%$ \\
\hline$p_{G A S_{-} N M M}$ & 111.6 & 163.4 & $+2.3 \%$ & 630.9 & $+10.7 \%$ \\
\hline$p_{G A S_{-} M A N}$ & 111.6 & 163.4 & $+2.3 \%$ & 630.9 & $+10.7 \%$ \\
\hline
\end{tabular}

Sources: see Annex C.1. The price of energy $i$ input into production $j$ is $p_{i j}$, with sector codes those of Table 1 . Unreported prices point at non-existing consumptions (e.g., no crude oil consumption by C\&S sector or by households). AAGR is the Average Annual Growth Rate.

The exogenous prices of oil and gas affect the supply costs of refined products and electricity via the hybrid input-output matrix. Under Transformation, on top of increased oil and gas prices, we assume reductions of the negative margins on the sales of refined products (which reflect the differential between the average resource price and the consumption prices of each sector and households) reaching $50 \%$ in 2030 . Likewise, we assume cuts on subsidies to electricity sales to both firms and households reaching $50 \%$ by 2030 . Both parameters remain constant throughout our projection horizon under Continuity.

Additionally, we adjust the capital intensity of the ELE sector to capture the impact of changes of the energy mix backing power supply. Under continued energy-pricing regulation, KEM projects the power mix to remain based on fossil fuels, although forecasting a gradual shift toward natural gas. Under reformed energy prices, it projects the power mix to shift to solar photovoltaic (PV) and nuclear sources (Matar et al., 2016). Using capital expenditure and operation and maintenance costs from Matar et al. (2016) and IEA (2016), and accounting for the low rates of capacity use at base-year as well as for the extra costs of handling intermittency in the case of solar PV, we translate KEM projections into a gradual decrease of the capital intensity of ELE in our Continuity 
scenario, reaching $20 \%$ in 2030 compared with base year; and, conversely, in a gradual increase of the capital intensity of ELE in our Transformation scenario, reaching 18\% in 2030 compared with base year.

Table C.2 reports the refined fuels (REF) and electricity (ELE) prices resulting from the above assumptions.

Table C.2: Projected consumer prices of refined products and electricity

\begin{tabular}{|c|c|c|c|c|c|}
\hline \multirow{2}{*}{$\begin{array}{l}\text { In SAR/ton-of-oil } \\
\text { equivalent }\end{array}$} & \multirow{2}{*}{$\begin{array}{r}\text { Calibration } \\
2013\end{array}$} & \multicolumn{2}{|c|}{------Continuity------ } & \multicolumn{2}{|c|}{------Transformation------ } \\
\hline & & 2030 & AAGR & 2030 & AAGR \\
\hline$p_{R E F_{-} E L E}$ & 85.4 & 147.2 & $+3.3 \%$ & $1,183.0$ & $+16.7 \%$ \\
\hline$p_{R_{E F_{-} C H M}}$ & 111.6 & 174.8 & $+2.7 \%$ & $1,205.9$ & $+15.0 \%$ \\
\hline$p_{R E F_{-} N M M}$ & 49.5 & 77.6 & $+2.7 \%$ & $1,151.7$ & $+20.3 \%$ \\
\hline$p_{R E F_{-} M A N}$ & 65.4 & 102.4 & $+2.7 \%$ & $1,165.5$ & $+18.5 \%$ \\
\hline$p_{R E F_{-} C P S}$ & 654.1 & 671.4 & $+0.2 \%$ & $1,679.4$ & $+5.7 \%$ \\
\hline$p_{R E F_{-} W T P}$ & 49.5 & 76.0 & $+2.5 \%$ & $1,151.7$ & $+20.3 \%$ \\
\hline$p_{R E F_{-} A T P}$ & 679.7 & 742.3 & $+0.5 \%$ & $1,701.7$ & $+5.5 \%$ \\
\hline$p_{\text {REF_OTP }}$ & 274.4 & 466.5 & $+3.2 \%$ & $1,348.0$ & $+9.8 \%$ \\
\hline$p_{E L E_{-} R E F}$ & $1,471.7$ & $1,510.7$ & $+0.2 \%$ & $3,106.0$ & $+4.5 \%$ \\
\hline$p_{E L E \_A G R}$ & $1,183.0$ & $1,214.4$ & $+0.2 \%$ & $2,724.0$ & $+5.0 \%$ \\
\hline$p_{E L E_{-} M I N}$ & $1,471.7$ & $1,812.9$ & $+1.2 \%$ & $3,106.0$ & $+4.5 \%$ \\
\hline$p_{E L E_{-} C H M}$ & $1,471.7$ & $1,812.9$ & $+1.2 \%$ & $3,106.0$ & $+4.5 \%$ \\
\hline$p_{E L E_{-} N M M}$ & $1,471.7$ & $1,812.9$ & $+1.2 \%$ & $3,106.0$ & $+4.5 \%$ \\
\hline$p_{E L E_{-} M A N}$ & $1,471.7$ & $1,812.9$ & $+1.2 \%$ & $3,106.0$ & $+4.5 \%$ \\
\hline$p_{E L E_{-} C P S}$ & $1,490.7$ & $2,540.2$ & $+3.2 \%$ & $3,131.2$ & $+4.5 \%$ \\
\hline$p_{C_{-} R E F}$ & 654.1 & $1,924.9$ & $+6.6 \%$ & $1,763.4$ & $+6.0 \%$ \\
\hline$p_{C_{-} E L E}$ & 581.5 & $1,796.4$ & $+6.9 \%$ & $4,891.0$ & $+13.3 \%$ \\
\hline
\end{tabular}

Sources: IMACLIM-SAU calibration and simulations. The price of energy $i$ input into production $j$ is $p_{i_{-} j}$, with sector codes those of Table 1. Unreported prices point at non-existing consumptions. AAGR is the Average Annual Growth Rate.

\section{C.2 Domestic energy flows}

We resort to the KAPSARC Energy Model KEM (see Matar et al., 2017, for an application with energy pricing reforms in the KSA) to settle the impact of the energy-pricing trajectories of Annex C.1 on the energy consumptions of six industrial sectors: oil and gas upstream activities, refining, electricity, water, petrochemicals and cement. These sectors cover $71 \%$ of total domestic consumptions in 2013 , the calibration year common to KEM and our own IMACLIM-SAU. To address the remainder of Saudi consumptions, we complement KEM outputs with the following assumptions. 
Considering Continuity energy prices, KEM projects an increase of crude oil and natural consumptions into power generation (includes water desalination in KEM) of 189\% and 60\% from 2013 to 2030 . For the remainder of firms' energy consumptions under Continuity, we assume constant energy intensities (constant amounts of energy input by a unit of output).

For households' consumptions, we assume that residential electricity demand grows at an average rate of $3.2 \%$ up to 2030 , which is 2 percentage points below 2007 -to-2016 average and close to the projected $2.8 \%$ increase of electricity demand for the Middle-East region by the IEA (2017) in its NPS. In fact, the first round of tariff reforms resulted in declines (for the first time) in 2016, 2017 and 2018 compared with historical growth of electricity consumption, making a structural decline of electricity demand growth plausible compared with its historical trend.

Concerning refined products, we assume that the fleet of light duty vehicles reaches 20 million units by 2030,5 $96 \%$ of which personal cars reflecting current shares reported by GSTAT. Moreover, we assume that fuel economy increases to reach average Corporate Average Fuel Economy (CAFE) standards of $17.1 \mathrm{~km} / \mathrm{l}$, up from 8 km/l in 2012 (Alabbadi, 2012) and consider IEA estimates of average annual car mileage (IEA, 2009). According to these assumptions, households' fuel uses increase $60 \%$ from 2013 to 2030 or at a $2.8 \%$ average annual rate (Table C.3).

Under the energy-pricing reforms of Transformation, KEM projects a phase-out of crude oil uses and a $77 \%$ decline of refined products uses (resulting from a phase-out of diesel uses) for power generation (including water desalination) between 2013 and 2030. We additionally assume that the hikes of energy tariffs combined with efficiency measures decrease the high energy intensity of the rest of the economy, reflecting wasteful and excessive energy consumptions (Fattouh and El-Katiri, 2013).

The multisector nature of IMACLIM-SAU allows differentiating efficiency assumptions by sector and energy vector based on additional external sources. We assume that the electricity intensity of industrial sectors decreases by $1.4 \%$ annually, corresponding to projected gain by ABB (2015) based on the Saudi National Energy Efficiency Program. For air and water transport, we consider annual efficiency gains at $2.0 \%$ and $1.1 \%$ up to 2030 .

\footnotetext{
${ }^{5}$ https://www.onlyelevenpercent.com/energy-efficiency-saudi-arabia/.
} 
Both gains derive from international benchmarks (see IEA, 2016 and ICAO, 2010). Finally, for industrial processes (i.e., consumption of OIL, GAS and REF by industrial branches MIN, CHM, NMM and MAN), we take up Soummane et al. (2019) aggregate assumption of $3 \%$ annual efficiency gains, close the $2.5 \%$ annual gains projected by IEA (2016) in its 450 Scenario up to 2040 . The weighted average of the above assumptions points at aggregate $2.7 \%$ annual energy-efficiency gains. Soummane et al. (2019) compute a low sensitivity of macroeconomic results to their $3 \%$ assumption by testing alternative $0 \%, 1 \%$ and $2 \%$ annual gains (see their Section 5.2).

For households' consumptions, we assume that Transformation pricing reforms allow containing the increase of residential electricity uses at the level of population growth (+33.2\% from 2013 to 2030). Regarding transport, we maintain the assumptions of the Continuity scenario except for fuel economy, which we assume to reach the upper bound of CAFE standards of $22 \mathrm{~km} / \mathrm{l}$ by 2030. As a result, households' fuel uses increase by $24 \%$ from 2013 to 2030 compared to $60 \%$ under Continuity (Table C.3).

It is important to stress that our assumptions on the energy consumptions of non-energy sectors take the form of intensities, i.e., consumptions per unit output rather than absolute consumptions. Thus, we take into account any discrepancy in sectoral activity between IMACLIM-SAU and that of KEM (see Matar et al., 2016 for the activity assumptions backing KEM). 
Table C.3: Assumptions on domestic energy consumptions

\begin{tabular}{|c|c|c|c|c|c|}
\hline \multirow{2}{*}{$\begin{array}{l}\text { Domestic energy use } \\
\text { (index } 1 \text { in 2013) }\end{array}$} & \multirow{2}{*}{$\begin{array}{r}\text { Calibration } \\
2013\end{array}$} & \multicolumn{2}{|c|}{------Continuity------ } & \multicolumn{2}{|c|}{------Transformation------ } \\
\hline & & 2030 & AAGR & 2030 & AAGR \\
\hline$\alpha_{O I L_{-} R E F}$ & 1.00 & 1.00 & id. & 1.00 & id. \\
\hline$\alpha_{O I L_{-} E L E}$ & 1.00 & 1.71 & $+3.2 \%$ & 0.00 & $-100.0 \%$ \\
\hline$\alpha_{O I L_{-} N M M}$ & 1.00 & 0.86 & $-0.9 \%$ & 0.60 & $-1.9 \%$ \\
\hline$\alpha_{O I L_{-} M A N}$ & 1.00 & 1.00 & id. & 0.60 & $-1.9 \%$ \\
\hline$\alpha_{G A S_{-} E L E}$ & 1.00 & 0.95 & $-0.3 \%$ & 0.93 & $-0.4 \%$ \\
\hline$\alpha_{G A S_{-} M I N}$ & 1.00 & 1.00 & id. & 0.60 & $-1.9 \%$ \\
\hline$\alpha_{G A S_{-} C H M}$ & 1.00 & 1.08 & $+0.4 \%$ & 0.60 & $-1.9 \%$ \\
\hline$\alpha_{G A S_{-} N M M}$ & 1.00 & 0.96 & $-0.3 \%$ & 0.60 & $-1.9 \%$ \\
\hline$\alpha_{G A S_{-} M A N}$ & 1.00 & 1.00 & id. & 0.60 & $-1.9 \%$ \\
\hline$\alpha_{R E F_{-} E L E}$ & 1.00 & 0.34 & $-6.1 \%$ & 0.20 & $-9.0 \%$ \\
\hline$\alpha_{R E F_{-} C H M}$ & 1.00 & 1.84 & $+3.6 \%$ & 0.60 & $-1.9 \%$ \\
\hline$\alpha_{R E F_{-} N M M}$ & 1.00 & 0.90 & $-0.6 \%$ & 0.60 & $-1.9 \%$ \\
\hline$\alpha_{R E F_{-} M A N}$ & 1.00 & 1.00 & id. & 0.60 & $-1.9 \%$ \\
\hline$\alpha_{R E F_{-} C P S}$ & 1.00 & 1.00 & id. & 1.00 & id. \\
\hline$\alpha_{R E F_{-} W T P}$ & 1.00 & 1.00 & id. & 0.83 & $-1.1 \%$ \\
\hline$\alpha_{R E F_{-} A T P}$ & 1.00 & 1.00 & id. & 0.71 & $-2.0 \%$ \\
\hline$\alpha_{R E F_{-} \text {OTP }}$ & 1.00 & 1.00 & id. & 0.80 & $-1.3 \%$ \\
\hline$\alpha_{E L E_{-} R E F}$ & 1.00 & 1.00 & id. & 1.00 & id. \\
\hline$\alpha_{E L E_{-} A G R}$ & 1.00 & 1.00 & id. & 0.78 & $-2.8 \%$ \\
\hline$\alpha_{E L E_{-} M I N}$ & 1.00 & 1.00 & id. & 0.78 & $-2.8 \%$ \\
\hline$\alpha_{E L E_{-} C H M}$ & 1.00 & 1.20 & $+1.1 \%$ & 0.50 & $-2.8 \%$ \\
\hline$\alpha_{E L E_{-} N M M}$ & 1.00 & 1.32 & $+1.7 \%$ & 0.78 & $-2.8 \%$ \\
\hline$\alpha_{E L E \_M A N}$ & 1.00 & 1.00 & id. & 0.78 & $-2.8 \%$ \\
\hline$\alpha_{E L E_{-} C P S}$ & 1.00 & 1.00 & id. & 0.78 & $-2.8 \%$ \\
\hline$C_{R E F}$ & 1.00 & 1.60 & $+2.8 \%$ & 1.24 & $+1.3 \%$ \\
\hline$C_{E L E}$ & 1.00 & 1.70 & $+3.2 \%$ & 1.33 & $+1.7 \%$ \\
\hline
\end{tabular}

The volume of energy $i$ input into production $j$ is $\alpha_{i j}$, with sector codes those of Table 1 . Households' consumption of energy good $i$ is $C_{i}$. Unreported volumes are non-existent. AAGR is the Average Annual Growth Rate. 


\section{C.3 Energy trade prices}

Oil trade accounts for $83 \%$ of Saudi exports earning, of which $73 \%$ are crude oil exports at around 7 million barrels per day (mb/d) during the past decade (SAMA, 2018). This makes crude oil price the main variable of interest for energy trade. Although OPEC supplies $40 \%$ of world oil demand, with Saudi Arabia acting as leader with $30 \%$ of the Organization's supply, its impact on oil price is not established. There is no agreement about OPEC's market power. Many authors argue that the 'cartel' strategy was established only during some periods, and that OPEC's strategy has been evolving (Fattouh and Mahadeva, 2013). Brémond et al. (2012) show that OPEC has been acting as a price taker for most of the period following the first oil shock (1973), and that cartel behavior only concerns a sub-group of the Organization. Some even argue that the cartel status of OPEC has never existed (Cairns and Calfucura, 2012). In the light of these claims, we assume that the KSA does not influence world prices and build both our Continuity and Transformation scenarios on a common exogenous assumption of the world oil price trajectory. Blazquez et al. (2017) adopt a similar specification.

We take this trajectory from the Sustainable Development Scenario (SDS) of IEA (2017). The dramatic oil-price decline of the end of 2014 resulted in historically low investment levels (IEA, 2016). Facing increasing global oil demand peaking only in the mid-2020s, the current under-investment in oil resources lifts the oil price up until 2025. From then on up to 2030, the global penetration of electric mobility and higher efficiency gains in the transport sector in addition to tightened climate policies cause global oil demand to decline, ending $16.6 \mathrm{mb} / \mathrm{d}$ or $16 \%$ lower than that of the less ambitious New Policy Scenario (NPS) in 2030. The oil price follows a similar trend, declining to 69 USD in 2030 or $26.6 \%$ below the price of the NPS scenario.

A fraction of Saudi energy exports consists of refined products. We link the price of such products to that of crude oil via a differential that we assume constant over time and across scenarios. We calibrate the differential as the ratio of the weighted average of the prices of exported petroleum products to the price of crude oil. The ratio is around 0.96 in 2013. Its low level stems from the fact that Saudi exports of refined products consist mainly of both heavy (fuel oil) and extra-light products (LPG and naphtha). ${ }^{6}$ Similarly to exports, we assume that the average import price of refined fuels is indexed on oil prices over our projection horizon and across scenarios.

\footnotetext{
${ }^{6}$ According to the 2013 Saudi energy balance (IEA, 2015), the export mix is $29 \%$ of LPG, $26 \%$ of naphtha, $24 \%$ of fuel oil, $10 \%$ of diesel, $9 \%$
} of kerosene and $2 \%$ of gasoline. 


\section{C.4 Energy trade flows and domestic supply}

The four energy goods disaggregated by IMACLIM-SAU separate in two groups as regards market balance: one group has exogenous domestic output and imports, and endogenous exports balancing resources and uses; the other group has exogenous imports and exports, and endogenous domestic output balancing resources and uses. Under Continuity, crude oil (OIL) and refined fuels (REF) belong to the former group and natural gas (GAS) and electricity (ELE) to the latter. Transformation moves OIL from the former to the latter group for reasons explained below.

Our Continuity scenario builds on the assumption that the Saudi output of crude oil reaches $12.7 \mathrm{mb} / \mathrm{d}$ by 2030 . This corresponds to the Saudi oil supply projected by the IEA (2017) in its NPS scenario, i.e. surmises that shifting from NPS to SDS (whose oil prices sustain both our scenarios, see Annex C.3 above) does not affect Saudi output, mostly directed to exports, considering its very low cost-see Annex E.4 of Soummane et al., 2019, for further discussion. Indeed, the KSA is considering reaching this level of output and could already do so by mobilizing its spare capacity (Krane, 2017). Concerning the output of refined products REF, our two scenarios share the assumption that the Saudi refining capacity will increase from the current level of $2.9 \mathrm{mb} / \mathrm{d}$ to $3.3 \mathrm{mb} / \mathrm{d}$ by 2030 , following up on the opening of the Jazan refinery $(0.4 \mathrm{mb} / \mathrm{d})$.

Imports of OIL, GAS and ELE are equal to zero in current statistics as well as in the outlooks of the KEM model sustaining our scenarios. IMACLIM-SAU simulations keep them so at all years and across scenarios. Imports of REF are not described by KEM and require some exogenous assumption. For lack of sources on the matter, we assume that they follow potential growth (the growth of efficient labor supply) i.e. increase by $45.7 \%$ from 2013 to 2030 under Continuity, while they keep at 2013 levels in the face of strongly abated domestic demand under Transformation.

Similarly to imports, exports of GAS and ELE are consistently equal to zero in statistics or KEM outlooks (see Matar et al., 2016). Regarding GAS, although the Kingdom is a major gas producer, all the production is directed to the domestic market. Regarding ELE, plans for regional market integration start to take effect but the traded volumes should remain negligible. We therefore keep both exports at zero across years and scenarios. 
Additionally to GAS and ELE, the Transformation scenario considers exogenous OIL exports. The reason is that the substantial crude oil savings induced by energy-pricing reforms would liberate large additional export capacities under the assumption of maintained output. We rather assume that Saudi Arabia contains crude oil exports to avoid flooding global oil markets thus further depressing the global oil price (Blazquez et al. 2017), and adjusts output accordingly. To facilitate scenario comparison, we set the OIL exports of Transformation at the endogenous levels that they reach under Continuity. This assumption brings crude oil output under Transformation $11.7 \%$ below Continuity levels in 2030 . The loss of export revenue is partially compensated by endogenous increases of REF exports flowing from maintained refining capacities and abated domestic demand. In 2030, refined products exports are $29.3 \%$ higher under Transformation than under Continuity. 


\section{Annex D}

\section{SENSITIVITY OF TRANSFORMATION TO STRUCTURAL CHANGE DRIVERS}

We test sensitivity of the Transformation scenario to its three major structural change drivers: energy price reforms, non-energy export boosts and corporate tax take-off. ${ }^{7}$ We exclude the Continuity scenario from the sensitivity analysis as this scenario corresponds to the business-as-usual case, which assumes an increase of already established activities without reforms of energy prices or corporate tax adjustment. Concerning energy prices (E prices), we run a low variant maintaining them at 2018 levels i.e. Continuity values, and a high variant considering a $75 \%$ rather than a $50 \%$ decrease of explicit and implicit energy subsidies at end-horizon (see Annex C.1). Concerning export trends ( $\mathrm{X}$ trends) of the two targeted sectors, i.e., MAN and C\&S, we run a low variant bringing down MAN and C\&S trends to default $+3.4 \%$ per year, and a high variant setting the MAN trend at $+15 \%$ per year and the C\&S trend at $+10.3 \%$ per year. This compounds into quadrupling C\&S exports by 2030 compared with targeted tripling in Transformation (see section 3.2). Finally, we test corporate tax rates at the lower and upper bounds of G20 countries, i.e., 19\% (low variant) and 35\% (high variant). We conduct the tests all other parameters equal.

Activity (GDP and employment), public accounts and $\mathrm{CO}_{2}$ emissions results appear qualitatively robust to the tested ranges, with altered Transformation scenarios systematically more favorable than Continuity (Table D.1). Activity responds particularly well to increased corporate taxes under the assumption of excess public surplus financing additional investment. Conversely, public budget balance and the net public debt are stable across variants because of the assumed $1 \%$ cap on budget surplus, which even the low corporate tax variant does not prevent reaching. $\mathrm{CO}_{2}$ emissions broadly follow activity for export trend and corporate tax variants. They expectedly respond to energy pricing, although with low (negative) elasticity because of energy intensities kept constrained at (implicitly controlled) Transformation levels (see Annex C.2).

\footnotetext{
${ }^{7}$ For the sake of concision, we refer to Soummane et al. (2019) for assessment of the influence of the global oil price on Saudi macroeconomic outlooks with a 2-sector 'KLEM' aggregation of IMACLIM-SAU.
} 
Table D.1: Sensitivity of Transformation to structural change drivers at $\mathbf{2 0 3 0}$ horizon

\begin{tabular}{|c|c|c|c|c|c|c|c|}
\hline Indicator & $\begin{array}{l}\text { Low } \mathrm{E} \\
\text { prices }\end{array}$ & $\begin{array}{l}\text { High E } \\
\text { prices }\end{array}$ & $\begin{array}{c}\text { Low X } \\
\text { trends }\end{array}$ & $\begin{array}{l}\text { High } \mathrm{X} \\
\text { trends }\end{array}$ & $\begin{array}{l}\text { Low } \\
\text { corp. tax }\end{array}$ & $\begin{array}{l}\text { High } \\
\text { corp. tax }\end{array}$ & Continuity \\
\hline Real GDP & $-0.4 \%$ & $+0.3 \%$ & $-0.6 \%$ & $+0.9 \%$ & $-0.5 \%$ & $+1.6 \%$ & $-1.3 \%$ \\
\hline $\begin{array}{l}\text { Trade balance, \% } \\
\text { GDP }\end{array}$ & $-0.1 \mathrm{pts}$ & $-0.1 \mathrm{pts}$ & $-2.5 \mathrm{pts}$ & $+3.2 \mathrm{pts}$ & $+0.4 \mathrm{pts}$ & $-1.1 \mathrm{pts}$ & +4.3 pts \\
\hline $\begin{array}{l}2013-2030 \text { trade } \\
\text { surplus }\end{array}$ & $-2.5 \%$ & $+0.6 \%$ & $-15.4 \%$ & $+16.8 \%$ & $+0.9 \%$ & $-2.9 \%$ & $+19.0 \%$ \\
\hline $\begin{array}{l}\text { Unemployment } \\
\text { rate }\end{array}$ & $-0.2 \mathrm{pts}$ & $+0.2 \mathrm{pts}$ & $+0.1 \mathrm{pts}$ & $-0.2 \mathrm{pts}$ & $+0.3 \mathrm{pts}$ & $-0.9 \mathrm{pts}$ & $+1.7 \mathrm{pts}$ \\
\hline $\begin{array}{l}\text { Public budget } \\
\text { balance, } \\
\% \text { GDP }\end{array}$ & $+0.0 \mathrm{pts}$ & -0.0 pts & -0.0 pts & $+0.0 \mathrm{pts}$ & $+0.0 \mathrm{pts}$ & $-0.0 \mathrm{pts}$ & $-6.2 \mathrm{pts}$ \\
\hline $\begin{array}{l}\text { Net public debt, } \\
\% \text { GDP }\end{array}$ & $+1.6 \mathrm{pts}$ & $-1.1 \mathrm{pts}$ & -0.0 pts & $+0.0 \mathrm{pts}$ & $+1.1 \mathrm{pts}$ & $-1.7 \mathrm{pts}$ & +35.9 pts \\
\hline $\mathrm{CO}_{2}$ emissions, $\mathrm{Mt}$ & $+2.4 \%$ & $-0.7 \%$ & $-0.7 \%$ & $+1.1 \%$ & $-0.4 \%$ & $+1.2 \%$ & $+125.4 \%$ \\
\hline
\end{tabular}

Source: IMACLIM-SAU simulations. "Pts" stands for percentage points. The table reports deviations from Transformation results in 2030.

The last column places Continuity relative to central parametrization Transformation for comparison purposes.

On trade, the high export trend variant brings the balance and surplus performance of Transformation close to that of Continuity-while it further increases the levels of activity and employment. This confirms the potential importance of non-oil, non-energy intensive trade in the successful diversification of the Saudi economy. Energy prices affect trade via contrary effects on the competitiveness of Saudi non-energy products, and the availability of refined products for exports, considering the adjustments of domestic demand (see Annex C.2). The corporate tax rate affects trade through the latter effect only, i.e. opposite to domestic refined fuels consumptions, which follow activity.

Finally, the high energy prices variant increases unemployment by reducing the purchasing power of households. This points at the necessity to factor in the ability of households to cut down their energy consumptions in reaction to energy pricing reforms. 


\section{References}

Note: this list of references only includes the additional references quoted in this Online Appendix. The references quoted in the main article are presented at the end of the main article.

ABB (2015). "Saudi Arabia: Energy efficiency report".

https://library.e.abb.com/public/3286e88f2467b11dc1257be80055df20/Saudi\%20Arabia.pdf.

Al Kaabi, F. (2016). "The Nexus between Remittance Outflows and GCC Growth and Inflation". Journal of International Business and Economics. June 2016, Vol. 4, No. 1, pp. 76-85.

https://doi.org/10.15640/JIBE.V4N1A7.

Alabbadi, N. M. (2012). "Energy efficiency in KSA: Necessity and expectations". Communication to The Second Annual Industrialist Workshop, Yanbu, Saudi Arabia. https://www.slidedoc.us/2nd-annual-indus-workshopyanbu-seec-may-2012-pptx.

APICORP, Arab Petroleum Investments Corporation (2018). "Saudi energy price reform getting serious". Vol. 03 No. 05, February 2018. http://www.apicorp-

arabia.com/Research/EnergyReseach/2018/APICORP_Energy_Research_V03_N05_2018.pdf

Billmeier, A. and D. S. Hakura (2008). "Trade Elasticities in the Middle East and Central Asia: What is the Role of Oil?". International Monetary Fund, WP/08/216.

https://www.imf.org/external/pubs/ft/wp/2008/wp08216.pdf.

Blazquez, J., L.C. Hunt, and B. Manzano (2017). "Oil Subsidies and Renewable Energy in Saudi Arabia: A General Equilibrium Approach." The Energy Journal 38(SP1): 29-45. https://doi.org/10.5547/01956574.38.SI1.jbla.

Brémond, V., E. Hache, and V. Mignon (2012). "Does OPEC still exist as a cartel? An empirical investigation". Energy Economics, 34(1), 125-131. https://doi.org/10.1016/j.eneco.2011.03.010.

Cairns, R. D. and E. Calfucura (2012). “OPEC: Market failure or power failure?” Energy Policy, 50, 570-580. https://doi.org/10.1016/j.enpol.2012.07.058.

CDSI (2014). National accounts 1435/1436 A.H. (2014). Central Department of Statistics and Information. The Kingdom of Saudi Arabia.

Fattouh, B., and L. El-Katiri (2013). "Energy subsidies in the Middle East and North Africa". Energy Strategy Reviews, 2(1), 108-115. https://doi.org/10.1016/j.esr.2012.11.004.

Fattouh, B. and L. Mahadeva (2013). "OPEC: what difference has it made?" Annual Review of Resource Economics, 5(1), 427-443. https://doi.org/10.1146/annurev-resource-091912-151901.

ICAO (2010). “Environmental Report 2010". International Civil Aviation Organization, Montreal. https://www.icao.int/environmental-protection/Documents/EnvironmentReport-2010/ICAO_EnvReport10Ch1_en.pdf.

IEA (2009). Transport energy and CO2: Moving toward sustainability. International Energy Agency, Paris, France.

IEA (2015). Energy Balances of non-OECD Countries 2015. International Energy Agency, Paris, France. 
IEA (2015). Energy Balances of non-OECD Countries 2015. International Energy Agency, Paris, France.

IEA (2016). World Energy Outlook 2016. International Energy Agency, Paris, France.

IEA (2017). World Energy Outlook 2017. International Energy Agency, Paris, France.

IMF (2016). "Saudi Arabia: 2016 Article IV Consultation". Press release; staff report; and informational Appendix.

https://www.imf.org/external/pubs/ft/scr/2016/cr16326.pdf. International Monetary Fund.

Jadwa (2018). "Update: Outlook on Crude Oil Refining in Saudi Arabia”. March 2018.

http://www.jadwa.com/en/download/outlook-on-crude-oil-refining-in-saudi-arabia/research-13-4-1-1-1-1-1.

Krane, J. and Y. H. Shih (2016). "Energy Subsidy Reform in the Persian Gulf: The End of the Big Oil Giveaway". Issue Brief no. 04.28.16. Rice University's Baker Institute for Public Policy, Houston, Texas.

https://www.bakerinstitute.org/files/10489/.

Krane, J. (2017) "Beyond 12.5: The implications of an increase in Saudi crude oil production capacity." Energy Policy 110: 542-547. https://doi.org/10.1016/j.enpol.2017.08.052.

Matar W., R. Echeverri, and A. Pierru (2016) "The Prospects for Coal-fired Power Generation in Saudi Arabia." Energy Strategy Reviews 13-14. https://doi.org/10.1016/j.esr.2016.10.004

Matar, W., F. Murphy, A. Pierru, B. Rioux, and D. Wogan (2017). "Efficient industrial energy use: The first step in transitioning Saudi Arabia's energy mix". Energy Policy, 105, 80-92.

https://doi.org/10.1016/j.enpol.2017.02.029.

Okagawa, A. and K. Ban (2008). "Estimation of substitution elasticities for CGE models". Discussion Papers in Economics and Business 08-16, Graduate School of Economics and Osaka School of International Public Policy, Osaka, Japan. http://www.esri.go.jp/jp/workshop/080225/03_report5_Okagawa.pdf.

SAMA (2018). "Annual Statistics 2018”. Saudi Arabian Monetary Authority. Retrieved from http://www.sama.gov.sa/en-US/EconomicReports/Pages/YearlyStatistics.aspx.

Soummane, S., Ghersi, F., \& Lefèvre, J. (2019). "Macroeconomic pathways of the Saudi economy: The challenge of global mitigation action versus the opportunity of national energy reforms". Energy Policy, 130, 263-282. https://doi.org/10.1016/j.enpol.2019.03.062. 